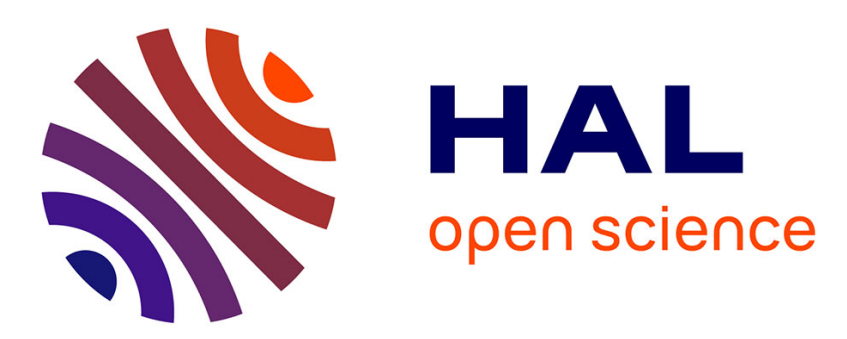

\title{
Modeling combustion chemistry in large eddy simulation of turbulent flames
}

Benoit Fiorina, Denis Veynante, Sébastien Candel

\section{To cite this version:}

Benoit Fiorina, Denis Veynante, Sébastien Candel. Modeling combustion chemistry in large eddy simulation of turbulent flames. Flow, Turbulence and Combustion, 2015, 94 (1), pp.3-42. 10.1007/s10494014-9579-8 . hal-01219272

\section{HAL Id: hal-01219272 \\ https://hal.science/hal-01219272}

Submitted on 28 Feb 2020

HAL is a multi-disciplinary open access archive for the deposit and dissemination of scientific research documents, whether they are published or not. The documents may come from teaching and research institutions in France or abroad, or from public or private research centers.
L'archive ouverte pluridisciplinaire $\mathbf{H A L}$, est destinée au dépôt et à la diffusion de documents scientifiques de niveau recherche, publiés ou non, émanant des établissements d'enseignement et de recherche français ou étrangers, des laboratoires publics ou privés. 


\title{
Modeling Combustion Chemistry in Large Eddy Simulation of Turbulent Flames
}

\author{
Benoît Fiorina · Denis Veynante · Sébastien Candel
}

\begin{abstract}
Flame ignition, stabilization and extinction or pollutant predictions are crucial issues in Large Eddy Simulations (LES) of turbulent combustion. These phenomena are strongly influenced by complex chemical effects. Unfortunately, despite the rapid increase in computational power, performing turbulent simulations of industrial configurations including detailed chemical mechanisms will still remain out of reach for a long time. This article proposes a review of commonly-used approaches to address fluid/chemistry interactions at a reduced computational cost. Several chemistry modeling routes are first examined with a focus on tabulated chemistry techniques. The problem of coupling chemistry with LES is considered in a second step. Examples of turbulent combustion simulations are presented in the final part of the article. Three LES applications are analyzed: a lean swirled combustor, a non-adiabatic turbulent stratified flame and a combustion chamber where internal recirculations promote the dilution of fresh gases by burnt gases.
\end{abstract}

Keywords Turbulent combustion · Large Eddy Simulation · Tabulated chemistry · Complex chemistry

\section{Introduction}

Combustion accounts for about $90 \%$ of the global consumption of primary energy [1]. Despite its environmental impact this share will probably not fall in the near future. Combustion delivers energy which is immediately available through the exothermic conversion of gaseous, liquid or solid fuels. There are no other way to provide energy which are as convenient and as effective. In automotive or aerospace applications, combustion provides

B. Fiorina $(\square) \cdot$ D. Veynante $\cdot$ S. Candel

Ecole Centrale Paris, Grande Voie des Vignes, 92295 Châtenay-Malabry, France

e-mail: benoit.fiorina @ecp.fr

B. Fiorina $\cdot$ D. Veynante $\cdot$ S. Candel

CNRS, UPR 288, Laboratoire d'Energétique Moléculaire et Macroscopique, Combustion (EM2C),

Grande Voie des Vignes, 92295 Châtenay-Malabry, France 
the required level of energy and the energy density of fuels is so large (about $40 \mathrm{MJ} \mathrm{kg}^{-1}$ for standard hydrocarbon fuels) that it gives a considerable autonomy to the vehicle which cannot be matched by other means. While automobiles may run with electrical engines and batteries, it is less easy to replace current gas turbine engines by an electrical propulsion system in transport aircraft. The very high energy density which can be obtained from chemical conversion of reactants is also essential to rocket propulsion.

Production of electrical energy also heavily relies on coal burning power plants and gas turbines (except in France where most of the electrical energy is produced by nuclear and hydraulic plants). One may think that the introduction of a greater amount of renewables like wind turbines or photovoltaics will reduce the need for fossil fuel powerplants. This is the case to some extent but renewable energy is essentially intermittent and wind turbines operate for about a quarter of the time. When production vanishes because of a lack of wind or sun and in the absence of massive capacities of electrical storage, the missing energy will have to be compensated. This is most readily accomplished by fossil fuel plants and gas turbines which can be rapidly mobilized. It is interesting and somewhat paradoxical to note that the greater reliance on renewables will require at least on a short term additional capacities to produce power from fossil fuels. One may also note that in some emerging countries, the demand for energy is quite high and leads a country like China to open a new coal powerplant every week or so. Combustion is also widely used to generate energy from renewable biomass. Finally, it is important to keep in mind that there are many other applications of combustion in industrial processes, waste incineration and safety.

In addition to being a way of transforming energy combustion generates green house gases like $\mathrm{CO}_{2}$, and pollutants like carbon monoxide $(\mathrm{CO})$, nitrogen oxides $\left(\mathrm{NO}_{x}\right)$, unburned hydrocarbons (HC), soot and other chemical species that have an adverse effect on human health and the environment, even in very small proportions, and need to be minimized. Environmental constraints and economic objectives drive a continuous search for more efficient combustion systems with reduced levels of pollutant emissions. Progress in this direction has been quite substantial with the simultaneous advances of a fundamental understanding of the basic mechanisms involved, enhanced diagnostics relying on lasers, optics and numerical imaging, improvements in experimental methodologies, developments in simulation software and high performance computing. Numerical modeling is now used on a routine basis in combustion research and engineering design. Because combustion raises many complex issues, there is no unique modeling method. While simple flames can be calculated by taking into account large kinetic schemes involving a few hundred species and a few thousand elementary reactions together with multi-species thermodynamics and transport, this is not possible when considering turbulent flames. In most practical applications, flows are turbulent because turbulence enhances mixing and promotes chemical conversion [2]. The description of turbulent combustion thus constitutes a central problem which requires a clever and well balanced handling of the complexities of the process. Prediction of the approximate length of a flame in a glass furnace does not need a detailed consideration of the chemical kinetics and a simplified one-step chemistry may well be sufficient to predict the burning velocity in turbulent premixed flames [3]. But this extreme simplification of chemical kinetics is no longer adequate when one wishes to consider phenomena which are sensitive to the chemical mechanisms such as the formation of pollutants like carbon monoxide, nitrogen oxides, unburned hydrocarbons or soot or to analyze ignition delays. These questions cannot be answered without taking into account some of the chemical kinetics complexity. Chemical composition and elementary reactions also influence flame stabilization in continuous combustion systems like gas turbines. In Internal 
Combustion Engines (ICE), fuel and air are diluted by Exhaust Gas Recirculation (EGR). The flame is then sensitive to low concentrations of radical species produced during the initiation phase of combustion. Ignition, but also flame propagation and interactions with walls are then strongly influenced by detailed chemistry effects. The challenges are even greater in the case of pollutant predictions because of their considerably smaller concentrations and the many pathways leading to their formation or destruction. Pollutant mole fractions amount to a few tenths to a few hundreds ppms while the main species are in much larger proportions (a few percentage points and about $70 \%$ for nitrogen which acts as a diluent). This large dynamic range constitutes a real challenge for predictions.

While there are uncertainties in reaction kinetics many detailed chemical mechanisms have been developed in recent years with an increasing degree of complexity to account for the chemical conversion of heavier hydrocarbons. Current schemes in combination with detailed models provide good predictions of laminar burning velocities of flames formed by light hydrocarbons like methane [4]. Heavier hydrocarbons like n-decane, the main constituent of kerosene, can also be considered with a reasonable degree of accuracy [5]. The determination of some polluting species, like soot, is not as firmly established but a basis is available which can be included in simulation models and may be used to guide analysis and design.

Introduction of detailed chemical kinetics in numerical simulations, raises difficult modeling issues and practical problems of computational strategy and resources. With the availability of high performance computational resources, Direct Numerical Simulations (DNS) including detailed chemistry have addressed complex situations like lifted jet flames [6], laboratory scale turbulent "V"-flame [7] and swirling flows [8, 9]. The review work from Chen [10] presents detailed chemistry DNS of lifted flame stabilization, premixed and stratified flame propagation in intense turbulence, and extinction and reignition in turbulent non-premixed jet flames. These direct numerical simulations (DNS) provide important insights in turbulent combustion knowledge. However such simulations, very expensive, exhibit important limitations on the the computational domain size, which does not in general exceed a few $\mathrm{cm}$ in the three directions.

Considerably less expensive than DNS, Large Eddy Simulation (LES) is an attractive way to predict flame dynamics and pollutant emissions in industrial combustion chambers. Reviews of methods and issues for LES of turbulent combustion have been proposed by Janicka \& Sadiki [11], Pitsch [12] and Gicquel et al. [13]. The coupling between LES and detailed chemistry is however challenging as it requires the establishment of closure laws for the rates of reactions and a strategy to reduce the complex kinetics to a computationally tractable description. These two aspects are considered in the following. One issue in LES is the definition of a model providing the spatially filtered reaction rates, a problem which has received considerable attention in recent years and which will be discussed later on in this article. This article first examines chemistry modeling routes. The central problem of coupling of chemistry with a large eddy simulation is considered in a second step. Examples of turbulent combustion simulations are discussed in the final part.

\section{Chemistry Modeling Routes}

This section reviews the various strategies developed to model reactive flows chemistry. The general mathematical formalism used to describe a reactive system is first introduced. The principal strategies developed to reduce the size of chemical mechanisms are then briefly 
presented and classified. The review mainly focuses on tabulated chemistry methods which aim at coupling chemical schemes to the flow by limiting the degree of freedom of the chemical space.

\subsection{Detailed chemistry formalism}

The thermo-chemical state of a system is described by the vector $\varphi$, which includes temperature, species mass fractions, and chemical reaction rates. $\varphi$ is identified from two state variables and from the chemical composition [14]. If the pressure $p$ and the temperature $T$ are retained as state variables, then a function $\mathcal{F}$ exists such that:

$$
\varphi=\mathcal{F}\left(p, T, Y_{1}, Y_{2}, \ldots, Y_{n_{s p}}\right)
$$

where $Y_{k}$ is the mass fraction of the $k^{t h}$ species and $n_{s p}$ is the total number of chemical species considered in the chemical mechanism.

For ideal gases, the mixture enthalpy $h$ and internal energy $e$ are respectively given by:

$$
\begin{gathered}
h=h^{0}+\int_{T^{0}}^{T} c_{p} d T \\
e=e^{0}+\int_{T^{0}}^{T} c_{v} d T
\end{gathered}
$$

where $c_{p}$ and $c_{v}$ are the specific heats of the mixture at constant pressure and volume, respectively. The superscript ${ }^{0}$ represents the reference state. The ideal gas law links the mixture density to the pressure, temperature and mixture composition by:

$$
\rho=\frac{p}{r T}
$$

where $r=R / W$ with $R=8.314 \mathrm{~J} . \mathrm{mol}^{-1} \cdot \mathrm{K}^{-1}$ the perfect gas constant and $W$ the mixture molar mass. Equations 2, 3 and 4 allow the substitution of the pair $(p, T)$ by $(p, h)$ or $(\rho, e)$. The thermochemical state may then be expressed in terms of these new sets of variables:

$$
\begin{aligned}
\varphi & =\mathcal{G}\left(p, h, Y_{1}, Y_{2}, \ldots, Y_{n_{s p}}\right) \\
\varphi & =\mathcal{H}\left(\rho, e, Y_{1}, Y_{2}, \ldots, Y_{n_{s p}}\right)
\end{aligned}
$$

In the direct coupling of chemical mechanism with reactive flow simulations, one balance equation must be solved for each chemical species involved in the chemical mechanism. The associated computational cost may become prohibitive for large chemical schemes. Even for simple flames the number of transport equations and state variables may become too large to allow easy convergence towards the solution.

\subsection{Chemical scheme reduction: from detailed to global chemistry}

\subsubsection{Detailed and skeletal mechanisms}

The objectives of detailed chemistry are to reproduce, with the highest possible precision, chemical pathways (or at least the most important pathways) involved in combustion. A detailed scheme is an exhaustive list of all possible elementary reactions between all species involved in the conversion process of a given fuel by an oxidizer. Ideally, a reference detailed scheme would be valid for the entire possible range of thermodynamical states (pressure, temperature) and compositions (fuel/air equivalence ratio, fuel and oxidizer dilution,...). However, even for the lighter hydrocarbons, there are no unique detailed kinetic schemes. 
Moreover, the development of detailed mechanism is also not the final answer to flame chemistry modeling. Indeed, mechanisms which are too large cannot be effectively used in multidimensional simulations of flames.

The first level of chemical scheme reduction consists in defining a skeletal mechanism, which eliminates the unimportant reactions and species that have a negligible contribution to the phenomena of interest. A skeletal mechanism which contains fewer elementary reactions than the detailed one is generated in this stage. Examples of procedures for the systematic reduction of mechanisms to a skeletal level are given in [15-18]. As the resulting skeletal mechanisms remain generally too large, a second level of simplification leading to reduced schemes is required for practical simulations .

\subsubsection{Reduced mechanisms}

Among methodologies to reduce chemical schemes, the distinction is made between "systematically reduced" and "empirically reduced". Systematically reduced mechanisms contain sets of global reactions whose rates are the linear combination of the rates of the elementary reactions participating in the detailed or skeletal mechanism. Empirically reduced mechanisms rely on global reactions featuring rates determined by tuning, guessing, and trial and error.

Systematically reduced mechanisms

Popular procedures to systematically reduce mechanism are the Quasi Steady-State approximation (QSSA) and/or the Partial Equilibrium approximation (PEA). QSSA assumes that the rate of production and destruction of a selection of species are much larger than their net rate of formation. This yields algebraic relations among the elementary rates. The PEA assumes that the rates of some reactions are so large that a partial equilibrium is established also giving rise to algebraic relations between the elementary reaction rates. An extensive description of these methods, which gives the mathematical framework and illustrations with practical examples, is given in the review article from [19].

Empirically reduced mechanisms

Empirical reduction aims at generating short mechanisms (from 1 to 4 steps in general), which capture global flame properties such as for example the burning velocity, the heat release rate, the burnt gas temperature and critical conditions for strain rate induced extinction. Pioneering work is due to Westbrook and Dryer [20] who proposed one and two global reaction steps with Arrhenius kinetics by tuning the pre-exponential factor, the activation energy and the reaction order. More recently, the applicability of one-step irreversible Arrhenius kinetics with unity reaction order to the description of partially premixed methane-air combustion has been investigated in [21]. For more complex hydrocarbons, a simple technique has been proposed $[22,23]$ to derive one-step and two-step schemes for kerosene-air flames. To fit the laminar burning velocity over a wide range of operating conditions, the pre-exponential constants of the two reactions are tabulated as a function of the local equivalence ratio. The fuel and oxidizer exponents are adjusted to reproduce dependence of premixed laminar burning velocity with mean pressure.

All studies conclude that activation temperature [21] or pre-exponential constant [22, 23 ] must depend on the equivalence ratio to recover the evolution of burning velocity over the whole flammability range. Methods have been recently developed to automatically optimize these chemical rate parameters [24]. An example of application is provided in [25] to calculate selective non catalytic reduction $\mathrm{DeNO}_{x}$ process.

Global mechanisms efficiently capture global flame properties such as flame propagation. However such simplified mechanisms cannot describe the chemical structure of the 
flame itself. Complex phenomena such as pollutant formation, flame extinction or ignition remain out of reach.

\subsection{Tabulated chemistry}

According to Pope [26], there are two distinctions to be made between tabulated chemistry methods. The first one (also called structured pre-tabulation [26]) developed in this article, includes all methods that couple chemistry to the flow through the two following steps: i) a preprocessing step where a thermo-chemical database (or a globally generated manifold [26]) is constructed by using a given detailed, skeletal or reduced mechanism. ii) the CFD computation step where the thermo-chemical look-up table is coupled to the reactive flow governing equations. At each numerical iteration, the reacting flow solver aims at predicting the flow field properties but also the look-up table coordinates. As the number of thermo-chemical look-up table coordinates is in general much lower than the number of species initially involved in the chemical scheme considered, tabulated chemistry constitutes a reduction methodology. The choice of coordinates (i.e. its number and definition) along with the procedure followed to fill-up and to access the chemical look-up table determines the degrees of freedom of the chemical system.

The terminology tabulated chemistry is also used in the literature to mention in situ adaptive tabulation (ISAT) [26], where a thermo-chemical table is built up during reactive flow computation. This table aims at speeding calculations of the chemical reaction rates encountered in detailed or skeletal mechanisms. In this sense ISAT is not a reduction method as the degree of freedom inherent to the considered mechanism is not affected and this type of method will not be given further consideration in what follows.

\subsubsection{Principle}

Tabulated chemistry aims at expressing the thermochemical variables in a reduced chemical state space, compared to detailed chemistry formalism. The set of species mass fractions involved in Eqs. 1, 5 or 6 are replaced by a reduced set of coordinates $\left(\psi_{1}, \psi_{2}, \ldots, \psi_{n}\right)$, where $n+2$ is the number of dimensions of the thermochemical database. Tabulated chemistry is efficient in comparison with detailed chemistry if $n<<n_{s p}$. In this new basis, the thermochemical variables $\varphi$ may be formally expressed as:

$$
\begin{aligned}
\varphi & =\mathcal{F}^{\prime}\left(p, T, \psi_{1}, \psi_{2}, \ldots, \psi_{n}\right) \\
\varphi & =\mathcal{G}^{\prime}\left(p, h, \psi_{1}, \psi_{2}, \ldots, \psi_{n}\right) \\
\varphi & =\mathcal{H}^{\prime}\left(\rho, e, \psi_{1}, \psi_{2}, \ldots, \psi_{n}\right)
\end{aligned}
$$

In practice, the mathematical functions $\mathcal{F}^{\prime}, \mathcal{G}^{\prime}$ or $\mathcal{H}^{\prime}$ do not have analytical expressions. They are usually defined in the discrete form of a database explaining the designation $t a b$ ulated chemistry. As the chemical database construction involves a chemical mechanism, tabulated chemistry is always a degraded representation of detailed (or skeletal) chemistry.

The key issues in the tabulated chemistry framework are to identify a suitable set of coordinates $\left(\psi_{1}, \psi_{2}, \ldots, \psi_{n}\right)$ and to generate the appropriate chemical database. The numerous strategies proposed for that purpose can be classified in two groups which rely on mathematical and physical analysis, respectively.

A pioneering mathematical technique for chemistry tabulation is the ILDM (Intrinsic Low-Dimensional manifold) method, devised by Maas and Pope [14]. This is based on a direct identification of the dynamic behavior of the nonlinear response of the chemical 
system. An attractor subspace is determined by examining the eigenvalues and eigenvectors of the system of equations and by neglecting and cutting-off fast time-scales smaller than a given time limit. Depending on the cut-off time-scale, one, two or more coordinates of this state space (equivalent to chemistry parameters) are sufficient to accurately reproduce the kinetic properties of the full reactive system. This attractor subspace is called manifold and the number of its coordinates corresponds to the minimum number of scalars that need to be transported to describe the full reactive system. In general, highly-reduced ILDM manifolds (maximum two coordinates) do not correctly reproduce the low-temperature regions of the flame, sensitive to molecular diffusion [27].

An alternative is to include physical consideration for designing the chemical database. This assumption is the foundation of flamelet models which assume that a turbulent flame front can be decomposed in a collection of 1-D flame elements. This strategy, developed for example by Peters [28] and Bradley et al. [29] for turbulent non-premixed and premixed flames respectively, is effective and well adapted to complex geometry reactors. Details and examples of flamelet based tabulated chemistry techniques are given in the following sections. The principal coordinates of tabulated chemistry are first introduced.

\subsubsection{Principal coordinates of tabulated chemistry}

The role of the chemical look-up table coordinates is to capture the impact of kinetics, molecular diffusion and heat losses on the flame structure. As the number and definition of the control variables depends on the modeling assumptions, there is no universal set of coordinates. Issues encountered in trying to represent the influence of dominant phenomena on combustion chemistry are discussed in the following.

Capturing mixing phenomena

Mixing between fuel and oxidizer streams is usually described by a conserved scalar, the mixture fraction $Z$. There are many possible definitions which depend on chemistry and transport modeling assumptions [2].

The simplest formulation of the mixture fraction can be derived for a single step chemistry of the type: $v_{F}^{\prime} F+v_{O}^{\prime} O \rightarrow P$ where $F, O$ et $P$ are fuel, oxidizer, and products, respectively and $v_{F}^{\prime}$ and $v_{O}^{\prime}$ denote molar stoichiometric coefficients. Assuming that molecular diffusivities are identical for all species, a possible definition of the mixture fraction is:

$$
Z=\frac{s Y_{F}-Y_{O}+Y_{O}^{o}}{s Y_{F}^{f}+Y_{O}^{o}}
$$

where superscripts ${ }^{o}$ and ${ }^{f}$ refer to the fuel and oxidizer stream properties, respectively and $s=v_{O}^{\prime} W_{O} / v_{F}^{\prime} W_{F}$ is the mass stoichiometric coefficient, corresponding to the mass of oxidizer needed per unit mass of fuel. The mixture fraction $Z$ is equal to 0 and 1 in the oxidizer and fuel streams, respectively.

This definition is not adapted to multi-step chemical schemes. Indeed, because of the presence of intermediate species, (10) does not ensure that $Z$ is a conserved scalar. A solution is to base the mixture fraction definition on the element (atomic) mass fractions $Y_{e}$ [30]. For each element $e$, a mixture fraction $Z_{e}$ is defined as follow:

$$
Z_{e}=\frac{Y_{e}-Y_{e}^{o}}{Y_{e}^{f}-Y_{e}^{o}}
$$

where $Y_{e_{f}}$ and $Y_{e_{o}}$ are the mass fractions of element $e$ in the fuel and oxidizer streams, respectively. Even in detailed chemistry situations, $Z_{e}$ always remains a conserved scalar. 
When assuming that all species have constant mass diffusivity $\left(\mathrm{Le}=\lambda /\left(\rho c_{p} D\right)=1\right)$, the mixture fraction definition does not depend on the chosen element $e\left(Z=Z_{1}=Z_{2}, \ldots=\right.$ $Z_{l}$, where $l$ is the total number of elements). Mixing between fuel and oxidizer is then captured by a unique dimension and $Z=Z_{e}$ is a conserved scalar described by a balance equation with no chemical source term:

$$
\frac{\partial \rho Z}{\partial t}+\frac{\partial \rho u_{i} Z}{\partial x_{i}}=\frac{\partial}{\partial x_{i}}\left(\rho D \frac{\partial Z}{\partial x_{i}}\right)
$$

where the molecular diffusion velocity is modeled by Fick's law. When differential diffusion of species is considered $\left(\mathrm{Le}_{k} \neq 1\right)$, mixing between fuel and oxidizer is not captured by a unique variable $Z_{e}$. Definition of $Z$ by Eq. 11 depends on the element considered $\left(Z \neq Z_{1} \neq Z_{2}, \ldots \neq Z_{l}\right)$. The degree of freedom of the systems increases from 1 to $l-1$. Tracking all mixing states then requires to solve a balance equation for each conserved scalar $Z_{e}$, which exhibits unclosed cross-derivative terms. Solutions have been recently proposed by Regele et al. [31], Verhoeven et al. [32] or Maragkos et al. [33] to capture differential diffusion within tabulated chemistry formulations. However, the computational cost and complexity of the look-up table generation are augmented. A solution is to allow the incorporation of differential diffusion effects by limiting fuel/oxidizer mixing to a single dimension. A single mixture fraction variable is used which is generally defined as a conserved scalar solution of Eq. 12 [34]. While this approach introduces errors as pointed out by Sutherland et al. [35] it also allows to incorporate differential diffusion features in turbulent flame simulations [36] without affecting the computational cost.

Many practical combustion applications cannot be treated as a two-streams mixing problem between fuel and oxidizer with fixed composition in each stream. This is the case for instance in MILD combustion [37], where reactions are strongly influenced by the rate of fresh gas dilution by burnt products. At least one supplementary coordinate is therefore needed to represent the chemical flame structure [38, 39]. A similar problem is observed when fuels with different compositions are injected into a combustion chamber. Two mixture fractions have been introduced for that purpose to capture a three-stream mixing problem [40, 41].

Tracking chemical reactions

The conversion from fresh to burnt gases is usually captured by a progress variable $Y_{c}$ which is generally defined by a combination of species mass fraction, selected to ensure a continuous and monotonic evolution of the progress variable between initial $\left(Y_{c}=Y_{c}^{f}\right)$ and final $\left(Y_{c}=Y_{c}^{b}\right)$ states. When this condition is satisfied, $\varphi\left(Y_{c}\right)$ is a mapping of $Y_{c}$ and the thermochemical variables can be tabulated in term of $Y_{c}$.

The importance of the definition of this progress variable $Y_{c}$ is illustrated in Fig. 1a which shows the projection of methane/air freely propagating adiabatic laminar flames onto the $\left(Y_{\mathrm{CO}_{2}}, T\right)$ space for different values of fresh gas equivalence ratio. From $\phi=0.4$ to $\phi=1.2$ the temperature expressed as a function of $\mathrm{CO}_{2}$ mass fraction is bijective, but in rich regions turning points exist. This phenomenon corresponds to the presence of $\mathrm{CO}_{2}$ and $\mathrm{CO}$ under rich conditions and at high temperature levels. At the same time, for equivalence ratios greater than 1.5, the temperature decreases when $\mathrm{Y}_{\mathrm{CO}_{2}}$ increases. Indeed, during the last chemical steps, where species react and progress towards the equilibrium state, endothermic reactions become more important than the exothermic ones and heat is absorbed instead of being released. A progress variable based on a linear combination of $\mathrm{CO}_{2}$ and $\mathrm{CO}$ mass 

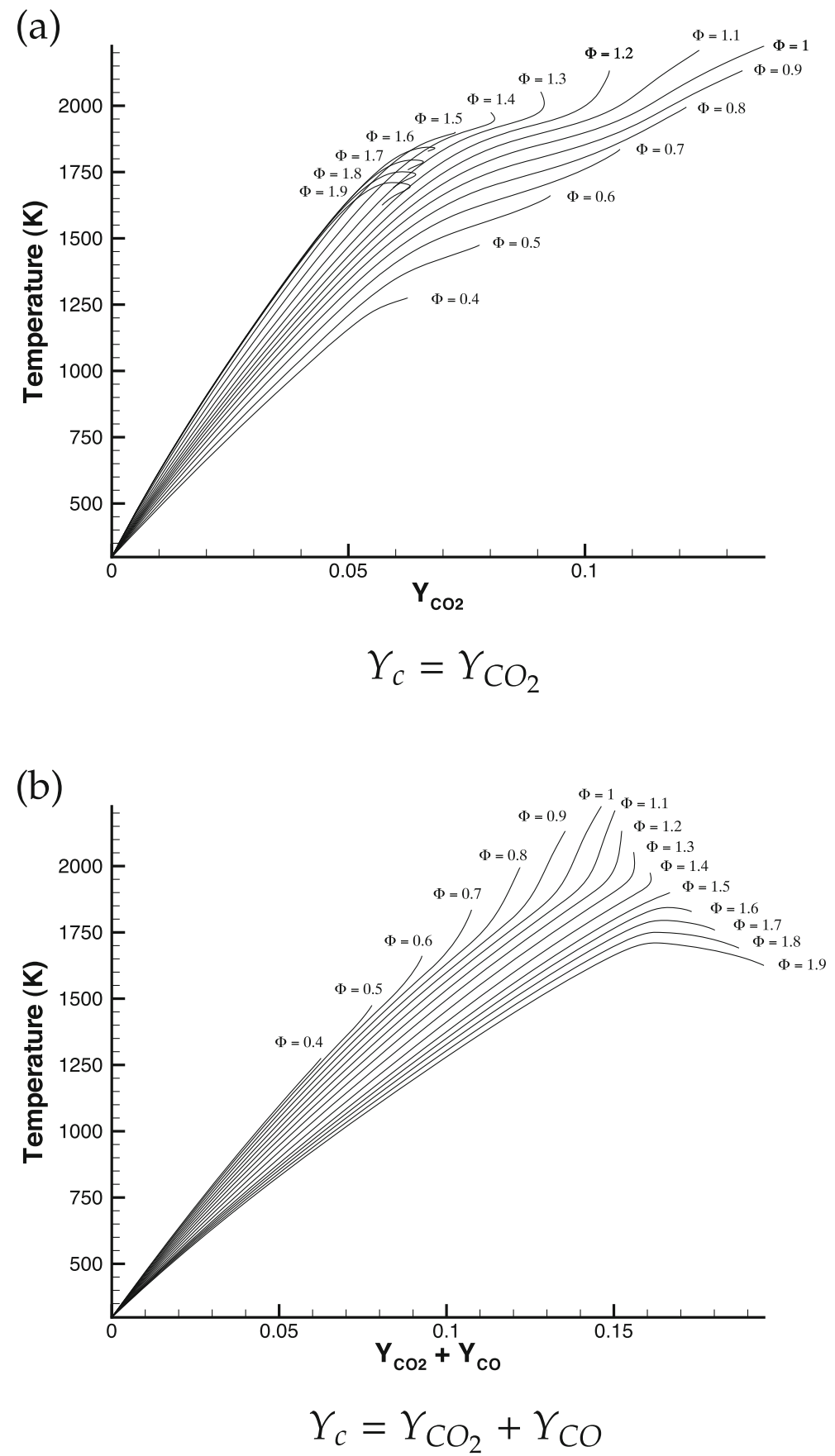

Fig. 1 Projection of 1-D premixed laminar flame trajectories in the plane $\left(Y_{c}, T\right)$ for two progress variable definitions. Each trajectory corresponds to a given value of fresh gases equivalence ratio $\phi$. From [44] 
fractions, $Y_{\mathrm{C}}=\mathrm{Y}_{\mathrm{CO}_{2}}+Y_{\mathrm{CO}}$, will reduce the importance of the turning point problem. Here the definition of the progress variable is based on a "user" knowledge but might be not optimal. Indeed minor species might still evolve in a non-monotonic fashion introducing some problems in the database exploitation. The progress variable definition may be facilitated by an automatic process which was recently devised by Ihme et al. [42] and Niu et al. [43].

The progress variable $Y_{c}$ is often normalized in a variable $c$, increasing from 0 in fresh to 1 in burnt gases [45]:

$$
c=\frac{Y_{c}-Y_{c}^{e q}}{Y_{c}^{f r}-Y_{c}^{e q}}
$$

where $Y_{c}^{e q}$ and $Y_{c}^{f r}$ correspond to $Y_{c}$ in fresh and burnt gases, respectively. In practice, $Y_{c}^{e q}$ corresponds to the value of $Y_{c}$ at the chemical equilibrium state. $Y_{c}^{e q}$, which depends on the initial mixture composition, is therefore strongly related to the mixture fraction $Z$.

The definition $Y_{c}=Y_{\mathrm{CO}_{2}}+Y_{\mathrm{CO}}$ is well adapted to the tracking of reactive and thermal layers, but alternative definitions of $Y_{c}$ are needed to capture phenomena that are out of the range of time scales associated to the formation of carbon monoxide and dioxide. This is the case of auto-ignition which exhibits time scales shorter than those of $\mathrm{CO}$ and $\mathrm{CO}_{2}$ production. To account for the ignition delay, the fuel mass fraction is added in the progress variable definition [46-49]. Another issue, related to the capture of $\mathrm{NO}_{x}$ produced through the thermal pathway, is illustrated in Fig. 2. Chemical trajectories followed by a collection of 1-D premixed flames are plotted in the $\left(Y_{c}, Y_{N O x}\right)$ chemical subspace. For a definition of $Y_{c}$ based on $\mathrm{CO}$ and $\mathrm{CO}_{2}$ species important variations of $\mathrm{NO}_{x}$ are not captured by the progress variable. The first solution, proposed by Oijen and de Goey [50] and Godel et al. [51] is to include a selection of nitrogen containing species in the definition of $Y_{c}$. NO trajectories are then mapped by $Y_{c}$, as shown in Fig. 2.

An alternative, which does not constrain the major products to the $\mathrm{NO}_{x}$ formation, is to introduce two progress variables: one is dedicated to tracking the flame thermal layer while the other describes nitrogen oxides [52, 53].

Accounting for heat exchanges

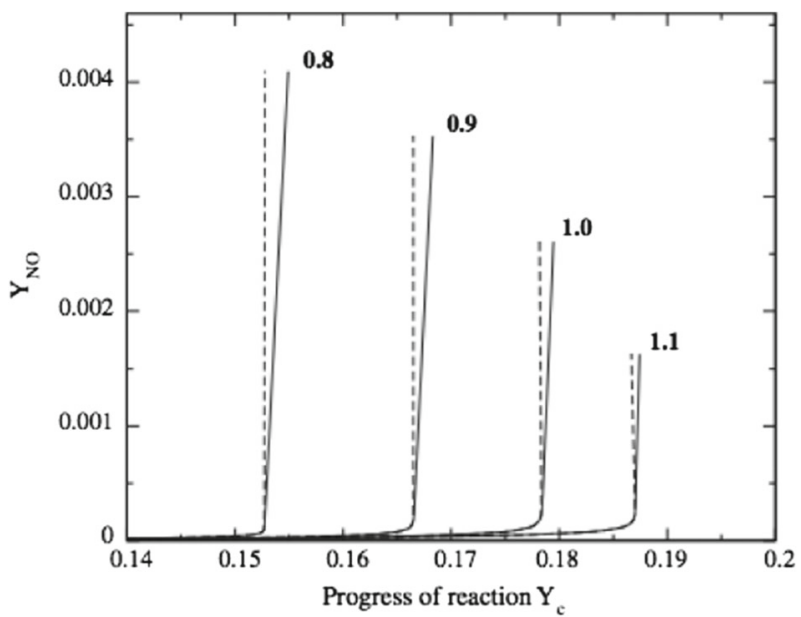

Fig. 2 Projection in the space $\left(Y_{N O}, Y_{c}\right)$ of 1-D premixed laminar flame trajectories obtained for different fresh gases equivalence ratios. Dashed: $Y_{c}$ is defined by $Y_{c}=Y_{C O}+Y_{C O_{2}}$. Solid : $Y_{c}$ is defined by $Y_{c}=$ $\mathrm{Y}_{\mathrm{CO}_{2}}+\mathrm{YCO}_{\mathrm{CO}}+\mathrm{Y}_{\mathrm{H}_{2} \mathrm{O}}+Y_{\mathrm{NO}}+Y_{\mathrm{NO}_{2}}+Y_{\mathrm{N}_{2} \mathrm{O}}+\Delta Y_{\mathrm{N}_{2}}$. Figure from [51] 
To use the total (i.e. sensible plus chemical) enthalpy

$$
h=\int_{T^{0}}^{T} c_{p} d T+h^{0}
$$

is convenient to track effects of heat exchanges. Indeed the tabulation procedure remains simple as the total enthalpy $h$ is conserved across constant pressure flames, for a given elemental composition. A normalized form of the enthalpy is generally introduced to facilitate the tabulation procedure :

$$
h_{n}=\frac{h-h_{\min }(Z)}{h_{a d}(Z)-h_{\min }(Z)}
$$

where $h_{a d}$ and $h_{\min }$ are the adiabatic and an arbitrary minimal mixture enthalpy, respectively.

\subsubsection{Flamelet based tabulation strategies}

An exhaustive review of strategies devised to build chemical look-up tables is out of the scope to the present article. Methods based on time scale analysis, mainly derived from Computational Singular Perturbation (CSP) [54] and Intrinsic Low Dimensional Manifolds (ILDM) [14] theories would be included but we decided to focus on flamelet-based tabulation techniques, which are well adapted to the simulation of many types of isobaric or nearly isobaric combustors. Again for the sake of compactness tabulated chemistry methods specifically designed for internal combustion engines, such as the Tabulated Kinetic of Ignition (TKI) model [55, 56], will not be discussed in here.

\section{Premixed flamelet tabulation}

Premixed flamelet tabulation has been first introduced in RANS computations of turbulent premixed and partially-premixed flames by Bradley et al. [29, 57]. By analyzing DNS results, Gicquel et al. [58] observed that the manifold covered by turbulent premixed flames are well approximated by the trajectory followed by a 1-D laminar flame element. By assuming that diffusion fluxes across mixture fraction iso-surfaces do not alter the chemical flame structure, the properties observed by Gicquel et al. [58] justify the mapping of the chemical trajectories accessed by a partially-premixed (or stratified) flame by a collection of premixed flamelets. A thermochemical look-up table is then built by solving, in a detailed chemistry framework, the governing equations of a planar laminar premixed flame. The inlet boundary conditions of the calculated flamelets are written in terms of the fresh gas equivalence ratio or mixture fraction $Z$ :

$$
T^{u}=T^{u}\left(Z^{u}\right), \quad Y_{k}^{u}=Y_{k}^{u}\left(Z^{u}\right) \quad \text { for } \quad Z_{l}<Z^{u}<Z_{r}
$$

where ${ }^{u}$ superscript refers to fresh gas conditions and $Z_{l}$ and $Z_{r}$ are the lean and rich flammability limits, respectively. The one-dimensional premixed laminar flame balance equations may be solved with a dedicated tool $[59,60]$, with the boundary conditions prescribed by Eq. 16. Solutions are then the thermochemical variables $\varphi$, expressed in term of $x$, the spatial coordinate normal to the flame front, and the mixture fraction $Z$ :

$$
\varphi=\varphi(Z, x)
$$

By definition, the progress variable $Y_{c}$ follows a monotonic and continuous evolution between fresh and burnt gas states in the spatial direction $x$, i.e. $Y_{c}$ is a bijective function of $x$. Then, any thermo-chemical variable $\varphi$ may be mapped as:

$$
\varphi=\varphi\left(Y_{c}, Z\right)
$$


To facilitate the management of the look-up table (data storage and interpolations), the coordinate $Y_{c}$ is generally normalized accordingly to Eq. 13. Within the flammability range, thermochemical data are in practice stored as follow:

$$
\varphi=\varphi(c, Z) \text { for } Z_{l}<Z<Z_{r}
$$

Outside the flammability range, chemical reactions rates are equal to zero. Under a unity Lewis assumption, species mass fractions and mixture enthalpy may be obtained from linear relations in $Z$ space (pure mixing) along iso- $c$ :

for $0<Z<Z_{l}$ :

$$
\begin{aligned}
& Y_{k}(c, Z)=\frac{Z}{Z_{l}}\left(Y_{k}\left(c, Z_{l}\right)-Y_{k}^{\text {oxy }}\right)+Y_{k}^{\text {oxy }} \\
& h(c, Z)=\frac{Z}{Z_{l}}\left(h\left(c, Z_{l}\right)-h^{\text {oxy }}\right)+h^{\text {oxy }}
\end{aligned}
$$

for $Z_{r}<Z<1$ :

$$
\begin{aligned}
& Y_{k}(c, Z)=\frac{Z-Z_{r}}{1-Z_{r}}\left(Y_{k}^{\text {fuel }}-Y_{k}\left(c, Z_{r}\right)\right)+Y_{k}\left(c, Z_{r}\right) \\
& h(c, Z)=\frac{Z-Z_{r}}{1-Z_{r}}\left(h^{\text {fuel }}-h\left(c, Z_{r}\right)\right)+h\left(c, Z_{r}\right)
\end{aligned}
$$

where superscripts fuel and $o x y$ characterize the fuel and oxidizer properties, respectively. Assuming constant pressure across the flame front, remaining thermochemical quantities such as the temperature are then deduced outside the flammability range from the vector of state variables $\left(p, h, Y_{k}\right)$.

An FPI chemical database is illustrated in Fig. 3, where the progress variable reaction rate is plotted in the $(c, Z)$ subspace. This tabulation procedure assumes that combustion occurs under adiabatic conditions. Accounting for effects of heat exchanges on the chemical flame structure requires to include flamelet solutions obtained under different enthalpy conditions in the look-up table. One solution is to calculate a series of burner-stabilized flames [44, 62]. Heat losses from each flamelet are controlled by the fresh gas mass flow rate injected through the porous burner. The enthalpy coordinate is then added to the chemical look-up table and each thermochemical variable $\varphi$ can be expressed in the form:

$$
\varphi=\varphi^{F P I}\left(h, Y_{c}, Z\right)
$$

Again, to facilitate database storage and requests, thermochemical variables are expressed in practice in terms of normalized coordinates:

$$
\varphi=\varphi^{F P I}\left(h_{n}, c, Z\right)
$$

Chemistry tabulation based on premixed flamelets are found in the literature under the acronyms FPI (Flame Prolongation of ILDM) [58] or FGM (Flamelet Generated Manifold) [62]. This strategy implicitly assumes that a turbulent stratified flame front can be decomposed in a series of independent premixed flamelets. This is true for low fuel/air mixing rates but is questionable when diffusion across mixture fraction isolayers becomes important. In such situations, the chemical flame structure is similar to a laminar diffusion flame and cannot be approximated by a collection of premixed flamelet archetypes anymore. This has been observed through a priori analysis of both 1-D counterflow detailed chemistry numerical solutions [63] and experimental measurements of turbulent jet flames [64]. When this happens the structure of the flame sheet is closer to that of a non-premixed flamelet. Chemistry tabulation based on 1-D diffusion flamelets, discussed below, is then more suitable. 


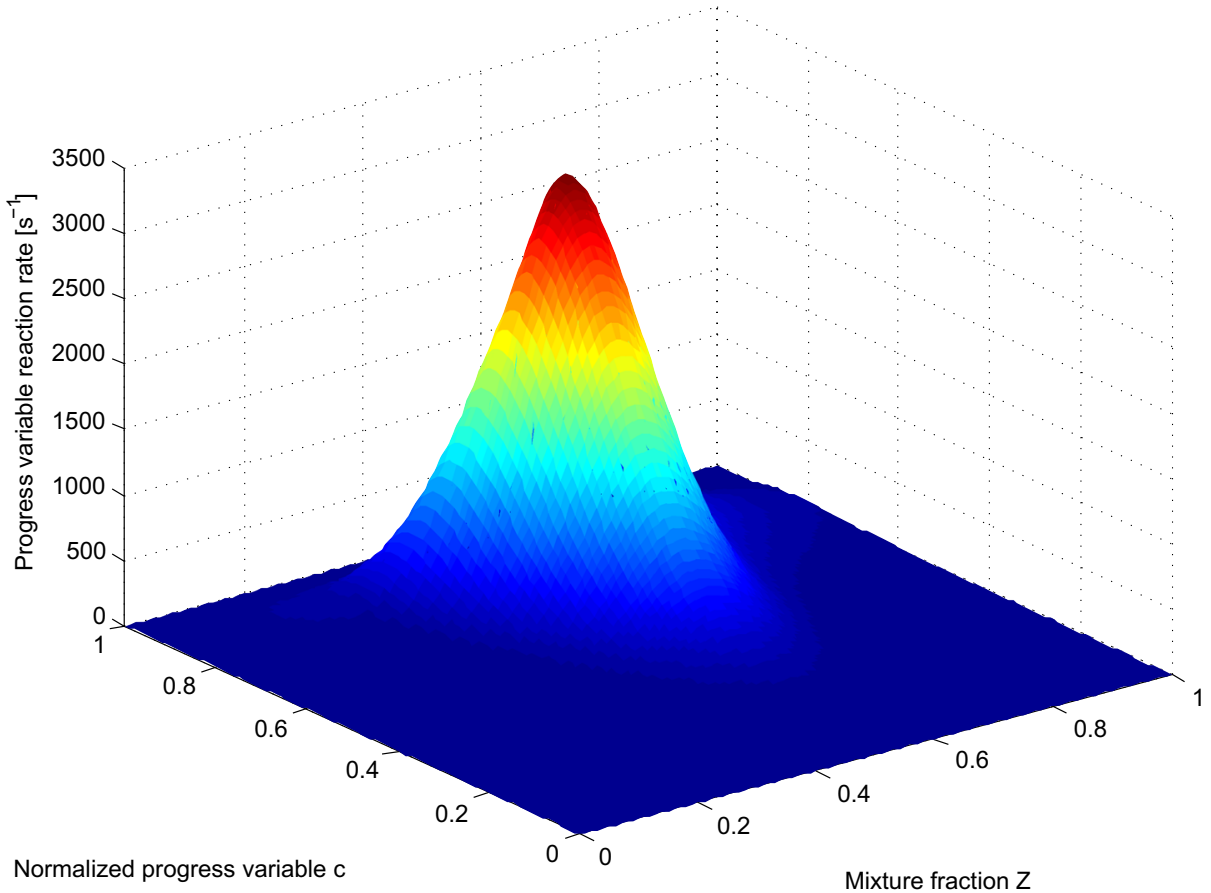

Fig. 3 Visualization of an FPI look-up table computed with the Lindsdedt mechanism [61] . Progress variable reaction rate tabulated in terms of normalized mixture fraction $(Z)$ and progress variable $(c) . Z=0$ and $Z=1$ correspond to pure air and to a methane - air mixture with equivalence ratio equal to 2 , respectively. The normalized progress variable $c$ is defined from Eq. 13 by making use of $Y_{c}=Y_{C O}+Y_{\mathrm{CO}_{2}}$

\section{Non-premixed flamelet tabulation}

To model non-premixed combustion, Peters [28] compiled strained steady diffusion flamelets in a thermochemical library. The flamelet equations are derived by assuming that the flame structure is locally one-dimensional and depends only on time and on the coordinate normal to the flame front [65]. The equations are generally expressed and solved in the mixture fraction space, where the impact of strain rate on the flame structure is governed by the scalar dissipation rate of the mixture fraction $\chi_{Z}=D_{Z}|\nabla Z|^{2}$. For instance, under unity Lewis number assumption, the species mass fractions are governed by:

$$
\rho \frac{\partial Y_{k}}{\partial t}=\chi_{Z} \frac{\partial^{2} Y_{k}}{\partial Z^{2}}+W_{k} \dot{\omega}_{k}
$$

where $\dot{\omega}_{k}$ and $W_{k}$ are the chemical molar reaction rate and molar mass of the $k^{\text {th }}$ species, respectively.

The scalar dissipation rate $\chi_{Z}$, which depends on flow conditions, must be modeled. In steady strained counter-flow, the scalar dissipation rate is expressed in terms of mixture fraction and $a$, the strain rate, through the following analytical function [66]:

$$
\chi_{Z}=\frac{a}{\pi} \exp \left(-2\left[\operatorname{erf}^{-1}(2 Z-1)\right]^{2}\right)=a F(Z)
$$


Introducing the stoichiometric scalar dissipation rate, $\chi_{Z_{s t}}=\chi\left(Z=Z_{s t}\right),(27)$ becomes:

$$
\chi(Z)=\chi_{Z_{s t}} \frac{F(Z)}{F\left(Z_{s t}\right)}
$$

Solving the system of Eqs. 26 and 28 under steady-state conditions for different values of stoichiometric scalar dissipation rates leads to the identification of thermo-chemical variables $\varphi$ :

$$
\varphi=\varphi^{S-S F M}\left(Z, \chi_{Z_{s t}}\right) \quad \text { with } \quad 0<\chi_{Z_{s t}}<\chi_{Z_{s t}}^{q}
$$

where S-SFM refers to Steady Strained Flamelet Model. In the previous expressions $\chi_{Z_{s t}}$ is the mixture fraction scalar dissipation rate conditioned by stoichiometric conditions. This formulation tracks steady states of non-premixed flames, from chemical equilibrium $\left(\chi_{Z_{s t}}=0\right)$ to quenching $\left(\chi_{Z_{s t}}=\chi_{Z_{s t}}^{q}\right)$. To account for re-ignition events, Pierce and Moin [67] added the unstable solutions of flamelet equations in the look-up table. The parametrization given by Eq. 29 is no longer suitable. Indeed, the S-curve plotted in Fig. 4 indicates that a given value of the scalar dissipation rate $\chi$ may correspond to stable, unstable and unburned states, a unique thermochemical state is not ensured. This issue is overcome by using the progress variable $Y_{c}$ instead of $\chi$ :

$$
\varphi=\varphi^{S-F P V}\left(Y_{c}, Z\right)
$$

where S-FPV stands for Steady-Flamelet Progress Variable. As the chemical trajectories are restricted to the steady state $S$-shaped response curve, phenomena which are unsteady such as auto-ignition events can not be captured by FPV look-up tables. To describe the transient evolution of all thermochemical variables during the flame ignition process, the solution of unsteady flamelet balance equations needs to be included [68, 69]. $\varphi$ variables are then parameterized in the form of:

$$
\varphi=\varphi^{U-F P V}\left(Y_{c}, Z, \chi_{Z_{s t}}\right)
$$

where "U-FPV" refers to Unsteady-Flamelet Progress Variable approaches. A third coordinate has been added to the steady state flamelet library to account for unsteady phenomena. Trajectories covered in the $\left(T_{s t}, \chi_{s t}\right)$ subspace by S-SFM, S-FPV and U-FPV chemical look-up tables are shown in Fig. 4. The S-SFM model covers the upper stable branch of the S-curve while S-FPV also includes the lower unstable branch. As a dimension has been added to the chemical database, the U-FPV approach relies on two coordinates in the subspace $\left(T_{s t}, \chi_{s t}\right)$.

An extension of the FPV model has been recently proposed by Lamouroux et al. [39] to account for the influence of burnt gas dilution. This formulation is specifically attractive in modeling of pollutant formation in flameless or MILD (Moderate or intense low oxygen dilution) combustors. In a non-adiabatic context, thermo-chemical variables then read as follows:

$$
\varphi=\varphi^{D-F P V}\left(Y_{c}, Z, \alpha, h_{n}\right)
$$

where "D-FPV" refers to Diluted FPV model. $\alpha$ is the rate of fresh gas dilution by burnt gases. Note that the influence of heat losses are accounted for by the variable $h_{n}$ defined in Eq. 15.

In parallel, the Combustion Group at the Eindhoven University of Technology introduced non-premixed flamelets in the FGM chemistry tabulation procedure [32, 70]. Steady and unsteady diffusion flamelets are used to generate 2D and 3D databases, respectively. 3D look-up tables appear to be more accurate to capture the chemical structure of unsteady flames [70, 71]. Large Eddy Simulations based on FGM constructed with non-premixed flames are exemplified in [72-74]. Tabulated chemistry methods based on non-premixed 
Fig. 4 S-curve characteristic of a methane/air flame. The fuel temperature is $298 \mathrm{~K}$ while the air stream has been preheated to $673 \mathrm{~K}$. Trajectories covered in the $\left(T_{s t}, \chi_{s t}\right)$ subspace by S-SFM, S-FPV and U-FPV chemical look-up table are shown by arrows. Projections of the manifold mapped by S-SFM and S-FPV are 1-D but 2-D for the U-FPV model

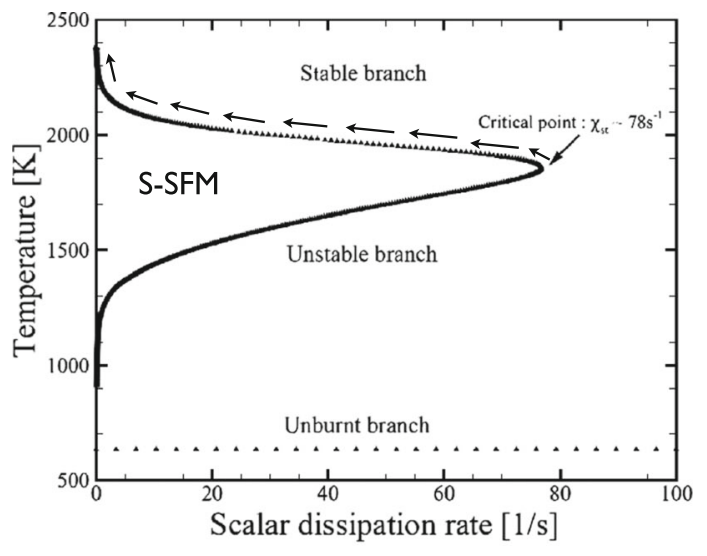

(a) Steady Strained Flamelet Model (S-SFM)

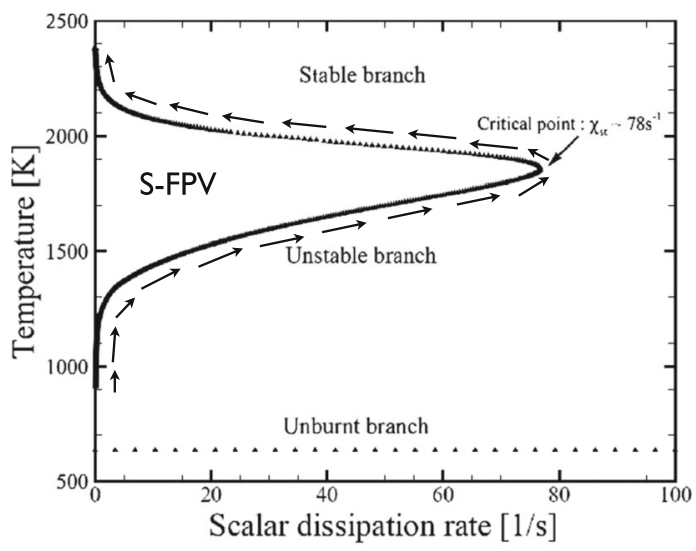

(b) Steady Flamelet Progress Variable (S-FPV)

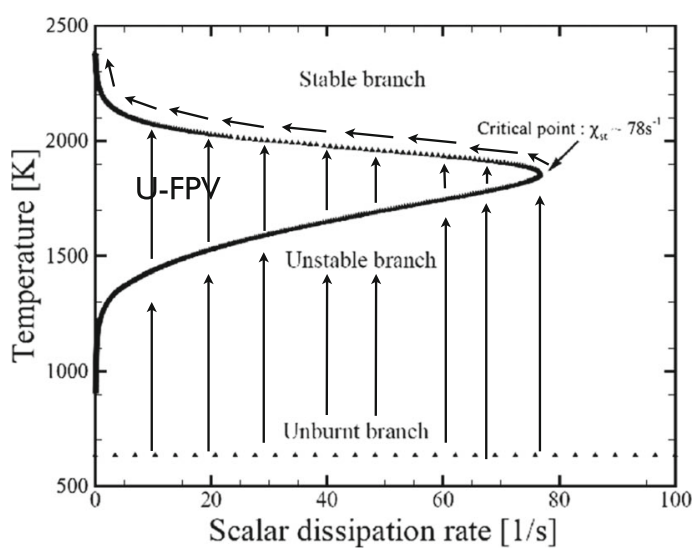

(c) Unsteady Flamelet Progress Variable (U-FPV) 
flamelets are obviously well adapted to model the chemical structure of diffusion flames but will fail to recover premixed flame properties, such as laminar flame speed [63]. To model complex flame elements which exhibit both premixed and non-premixed flame structures, multi-regime flamelet tabulation are required.

Multi-regime flamelet tabulation

To track multiple flamelet regime within a single look-up table, Bykov and Maas [75, 76] and Nguyen et al. [77] proposed to solve the projection of the full set of mass conservation species balance equations into a restricted subset of the composition space. Assuming that for partially premixed combustion the chemical system is well characterized in the $Z-Y_{c}$ subspace, a chemical table is computed by solving the following system of species equations:

$$
\rho \frac{\partial Y_{k}}{\partial t}+\frac{\partial Y_{k}}{\partial Y_{c}} \dot{\omega}_{Y_{c}}=\rho \chi_{Y_{c}} \frac{\partial^{2} Y_{k}}{\partial Y_{c}^{2}}+\rho \chi_{Z} \frac{\partial^{2} Y_{k}}{\partial Z^{2}}+2 \rho \chi_{Y_{c}, Z} \frac{\partial^{2} Y_{k}}{\partial Y_{c} \partial Z}+W_{k} \dot{\omega}_{k}
$$

where unity Lewis number has been assumed. The chemical look-up table is parametrized by the dimensions $Y_{c}$ and $Z$ but also by the scalar dissipation rates of the control parameters: $\chi_{Z}=D|\nabla Z|^{2}, \chi_{Y_{c}}=D\left|\nabla Y_{c}\right|^{2}$ and $\chi_{Y_{c}, Z}=D \nabla Y_{c} \cdot \nabla Z$. Analytical models for $\chi_{Z}, \chi_{Y_{c}}$ and $\chi_{Y_{c}}, Z$ can then be used to integrate the multi-regime flamelet equations expressed in the $\left(Y_{c}, Z\right)$ subspace. Thermo-chemical variables are then expressed as follows:

$$
\varphi^{M F}\left(Y_{c}, Z, \chi_{Z}, \chi_{Y_{c}}, \chi_{Y_{c}, Z}\right)
$$

The addition of the scalar dissipation rates as control parameters increases the number of look-up table coordinates enabling the modeling of complex flame structures. An alternative, proposed by Franzelli et al. [78] is to solve multi-regime flamelet equations in physical space. Premixed, partially-premixed and non premixed flame solutions are then merged and mapped into a multi-dimensional chemical look-up table. A priori tests on 1-D counterflow flame configuration show that multi-regime chemical look-up table are required to accurately describe pollutant formation such as carbon monoxides [78] and other species which are sensitive to the chemistry details.

Accounting for differential diffusion effects

A single mixture fraction coordinate is not sufficient to describe the fuel/air mixing when differential diffusion needs to be accounted for. This issue drastically increases the complexity of the tabulation process as it requires the addition of several coordinates [58], leading to high-dimensional databases. Preferential diffusion can be included by tabulating strained flame responses as a function of elemental mass fractions, enthalpy and a progress variable [79]. This method has been applied to perform DNS of a lean premixed turbulent Bunsen flame with hydrogen addition [80]. In a laminar context, Regele et al. [31] applied a technique to account for fuel differential diffusion phenomena within tabulated chemistry by adding a source term to the mixture fraction balance equation. A similar method has been recently developed for turbulent flames and applied in an LES context by Nambully et al. [81]. For premixed flamelet tabulations, an intermediate solution which does not increase the number of look-up table dimensions, is simply to generate the look-table with 1-D flame elements computed under differential diffusion assumptions. It neglects the impact of differential diffusion in the direction tangential to the flame front (i.e. between each flamelet). However, the species differential diffusion in the direction normal to the flame is captured by the 1-D premixed flamelet elements and allows to correctly predict the laminar flame consumption speed [36]. 


\subsubsection{Tabulated chemistry and CFD}

Low Mach number and compressible flow formalisms

Low Mach number assumptions are generally retained to generate thermo-chemical look-up tables. If the reactive flow governing equations are also expressed for low Mach conditions, then the chemistry tabulated formalism is consistent and its implementation straightforward. All thermo-chemical variables are directly estimated, for each numerical iteration, from linear interpolation within the chemical look-up table. For instance, density and temperature of adiabatic reactive flows are expressed in the form:

$$
\begin{aligned}
\rho & =\rho^{t a b}\left(\psi_{1}, \psi_{2}, \ldots, \psi_{n}\right) \\
T & =T^{t a b}\left(\psi_{1}, \psi_{2}, \ldots, \psi_{n}\right)
\end{aligned}
$$

Issues appear in the coupling with compressible Navier-Stokes equations, in particular when compressible effects are not considered during the database generation. By comparison with an adiabatic and isobaric low Mach number flow, the compressible formalism introduces two degrees of freedom which are for instance the pair $(e, p)$ or $(e, \rho)$. Even if the flow is adiabatic, the internal energy varies locally because of acoustic pressure waves.

To couple an adiabatic chemical table with a compressible flow solver, Galpin et al. [82] proposed to solve, in addition to the reduced set of variables, balance equations for some chemical species selected to estimate the temperature from energy. This implementation does not require heavy modifications of the flow solver but increases the number of equations. In addition, a divergence between the additional transported species and the tabulated ones is frequently observed and requires a specific treatment.

An alternative, called TTC (Tabulated Thermo-chemistry for Compressible flows) has been proposed by Vicquelin et al. [83]. The first order truncated Taylor expansion of $e$ around $T=T^{t a b}$ leads to the following linear approximation of the temperature:

$$
T=T^{t a b}\left(\psi_{1}, \ldots, \psi_{n}\right)+\frac{e-e^{t a b}\left(\psi_{1}, \ldots, \psi_{n}\right)}{C_{v}^{t a b}\left(\psi_{1}, \ldots, \psi_{n}\right)}
$$

The "compressible" temperature $T$ can therefore be approximated from the energy and temperature $e^{t a b}$ and $T^{t a b}$ which are both tabulated in an adiabatic look-up table. The energy $e$ which accounts for acoustic perturbations is transported. Note that this assumption is valid for moderate acoustic perturbations inducing small temperature variations. It is justified when combustion operates at constant pressure such as in gas turbines, furnaces, unconfined laboratory flames, etc... Other practical situations exist where pressure variations are sufficiently large to affect the chemistry (internal combustion engines, detonation waves, ...) and extra-coordinates have to be added to the chemical database.

Finally the introduction of tabulated chemistry in compressible CFD requires a careful treatment of boundary conditions. For that purpose, Vicquelin et al. [83] reformulated the Navier-Stokes Characteristic Boundary Conditions (NSCBC) derived by Poinsot and Lele [84].

\section{Managing chemical table storage}

In a parallel computational framework, chemical databases are loaded in the local memory of each processor to minimize data exchanges. Then, the chemical database size may become a problem when handling a large number of coordinates. This issue is of crucial importance when running on massively parallel computers having a limited amount of memory per processor. Some strategies has been developed to limit the chemical database sizes. For example, ISAT (In Situ Adaptive Tabulation) proposed by Pope [85] relies on the in situ generation of look-up tables, which are constructed from the direct solution of time 
evolution equations for species mass fractions. Only the chemical composition effectively accessed during the computation are calculated and stored in the chemical table. An alternative to reduce the database size is to introduce optimal neural networks to approximate chemical tables [86, 87].

Another simplification in the framework of flamelet tabulation has been devised by Ribert et al. [88]. It exploits self-similar properties of laminar flames to reduce the database memory requirements. Species reaction rates expressed as a function of a progress variable are found to reduce to single curves when using suitable scaling rules. This methodology has been recently extended to capture auto-ignition situations including cool-flame burning regime [89]. This strategy has been extended to turbulent regimes by taking advantage of self-similar properties of mean chemical quantities under a presumed probability density function formalism $[41,90]$. This idea has been successfully applied to the RANS simulation of a turbulent jet flame [91].

A different strategy recently proposed by Weise et al. [92] relies on a Memory Abstraction Layer (MAL) that handles requested chemical look-up table entries efficiently by splitting the database file into several smaller blocks. The method keeps the total memory usage at a minimum by employing thin allocation methods and compression to minimize filesystem operations. The efficiency of the method has been demonstrated on the simulation of laminar and turbulent non premixed flames [92].

\section{Coupling Chemistry with LES}

One of the central issues for large eddy simulation in combustion is to couple the chemistry description to the flow solver. This section summarizes the different approaches derived to model reaction rates in this framework. These may be classified with respect to the following two points:

Flame / Turbulence interactions: primary modeling concepts may be based on flame surface, statistical and mixing formalisms, as described in the following sections. ${ }^{1}$

Chemistry description: The simplest description is to assume that chemical time scales are faster than turbulence scales. Under this condition, the turbulent eddies do not alter the laminar chemical flame structure. The flame is then viewed as a collection of laminar flame elements (flamelet assumption), leading to global descriptions ("mixed is burnt" for non-premixed flames or infinitely thin propagating flame surface for premixed flames). More refined approaches involve simple chemical step, reduced global chemical schemes, skeletal schemes, tabulated chemistry, detailed chemical mechanisms as described in the previous section.

\footnotetext{
${ }^{1}$ Note that several concepts may be combined. For example, partial premixing (i.e., heterogenous equivalence ratio fields) are generally incorporated in flame surface concepts through mixture fraction probability density functions. The wide range of chemical time scales may also be handled combining several formalisms: the fuel oxidation, generally occurring in thin reaction layers may be described in terms of flame surface densities while the slow $N O x$ formation modeled through turbulent mixing concepts. The classification proposed here is based on the primary modeling concept, flame surface for the previous example.
} 
Most of the combinations (flame / turbulence interaction, chemical description) are theoretically possible but not necessarily of practical interest. A third dimension for classification is the practical implementation, considering assumptions made in the solver developments (fully compressible or low Mach number frameworks) or efficient chemistry implementations, for example through the ISAT formalism [85].

Compared to the Reynolds Averaged Navier-Stokes (RANS) formalism, two specific issues should be considered (i) First, the instantaneous flame front thickness is generally smaller than the typical mesh size, usually directly linked to the filter size. Combustion is mainly a sub-grid scale phenomenon while most of the turbulence energy is contained in large resolved scales. Models should be adapted to overcome this difficulty but, up-tonow, only flame surface formalism derivations explicitly consider this point and, in practice, the resolved flame thickness is mainly controlled by numerics in most models ; (ii) LES models should be able to reproduce laminar flames when sub-grid scale turbulence vanishes. In contrast most of the RANS models are derived in the limit of high Reynolds number turbulence and do not behave correctly when applied in the laminar flow limit. One may remember that LES is expected to reduce to DNS when the filter size becomes vanishingly small $(\Delta \rightarrow 0)$. In addition, in the computational meshes accessible today, the flame front wrinkling may become fully resolved in some parts of the numerical domain [93].

Conceptually, the Large Eddy Simulation formalism introduces a numerical length scale, the filter size $\Delta$, in the turbulent combustion problem. To compare this new practical scale to turbulence and combustion length scales led Pitsch $[12,94]$ to revisit premixed combustion regime diagrams.

\subsection{Geometrical approach}

Geometrical formulations, designed to capture the flame front propagation, are well adapted to premixed or stratified combustion regimes. Three main approaches have been developed describing the flame in terms of flame surface and managing the flame thickness issues discussed previously: $G$-equation, filtered one-dimensional flames and thickened flame model.

\subsubsection{Level set or "G-equation” formalism}

In this approach, the flame surface is viewed as an infinitely thin propagating surface (flamelet). The key idea is to track the position of the flame front using a field variable $G$. This $G$-field, generally identified to a signed distance to the flame front, does not have to follow the gradients of the progress variable $c$ and can be smoothed out to be resolved on the LES mesh. The $G$-equation is introduced by Kerstein et al. [95]:

$$
\frac{\partial G}{\partial t}+\widetilde{\mathbf{u}} \cdot \nabla G=S_{T}|\nabla G|
$$

where $S_{T}$ is the sub-grid scale turbulent burning velocity that should be modeled. Equation 38 corresponds to a simple kinematic description and its coupling with the density field through heat release requires some care [96-98]. However, despite some drawbacks, this approach has become one of the most commonly used in large eddy simulations of premixed combustion [12, 66, 94, 97, 99-105]. It is also well-suited to large computational domains as the inner structure of the turbulent flame brush does not need to be resolved. 


\subsubsection{Filtering laminar flames}

\section{Basic principles}

Applying the LES filter $F$ to the reduced progress variable $c=Y_{c} / Y_{c}^{e q}$ balance equation in premixed combustion ( $c=0$ within fresh reactants and $c=1$ within burnt products, $Y_{c}^{e q}$ being the $Y_{c}$-equilibrium value) leads to the following expression:

$$
\begin{aligned}
\frac{\partial \bar{\rho} \widetilde{c}}{\partial t}+\nabla \cdot(\bar{\rho} \widetilde{\mathbf{u}} \widetilde{c})+\nabla \cdot[\bar{\rho}(\tilde{\mathbf{u}} c-\widetilde{\mathbf{u}} \widetilde{c})] & =\overline{\nabla \cdot(\rho D \nabla c)}+\overline{\dot{\omega}}_{c} \\
& =\overline{\rho w|\nabla c|}
\end{aligned}
$$

where $\bar{Q}$ and $\widetilde{Q}=\overline{\rho Q} / \bar{\rho}$ denote filtered and mass-weighted filtered quantities, respectively. The three LHS terms correspond respectively to unsteady effects, resolved convective fluxes and unresolved transport. The two RHS terms in Eq. 39 respectively denote filtered molecular diffusion and filtered reaction rate. The RHS term in Eq. 40 corresponds to flame front displacement.

As already pointed out, the flame front is generally too thin to be resolved on the LES computational mesh. Nevertheless, the filtered progress variable $\tilde{c}$ may be resolved using a physical space Gaussian filter with a filter size $\Delta$ larger than the computational mesh size $\Delta_{m}$ as shown in Fig. 5 [106]. Accordingly, the filtered flame front is numerically resolved with about $2 \Delta / \Delta_{m}$ grid points. The $\widetilde{c}$-balance (40) is similar to a $G$-equation but, compared to an arbitrary $G$-field, the progress variable $c$ has the important advantage of being related to quantities that are physically defined and may be extracted from DNS or experimental data.

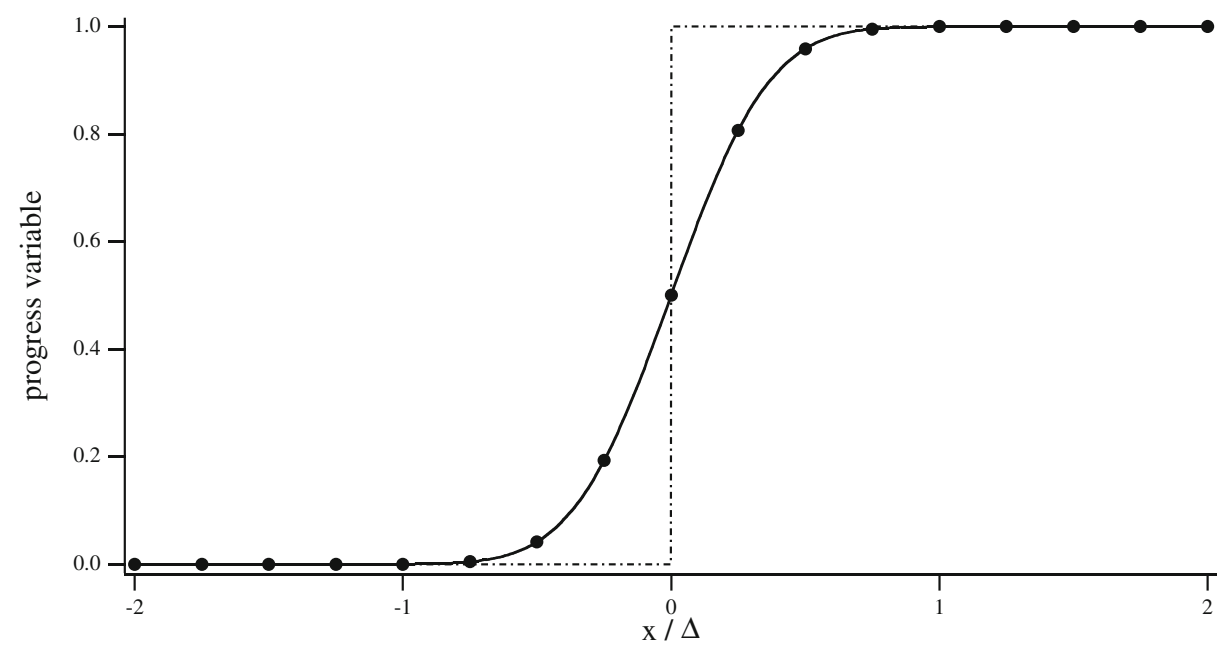

Fig. 5 Effect of a spatial Gaussian filter having a size $\Delta$ larger than the mesh size $\Delta_{m}\left(\Delta=4 \Delta_{m}\right)$. The unfiltered progress variable $c$ (dashed-dotted line) and the filtered progress variable $\bar{c}$ (bold line) are plotted as a function of $x / \Delta$ where $x$ is the spatial coordinate. The progress variable $c$ is not resolved on the computational mesh denoted by (• symbols) whereas the filtered progress variable $\bar{c}$ is resolved with about $2 \Delta / \Delta_{m}=8$ grid points inside the filtered flame front. From Boger et al. [106] 
Boger et al. [106] then propose a flame surface density formulation for subgrid scale modeling. The flame front displacement may be recast as:

$$
\begin{aligned}
\overline{\rho w|\nabla c|} & =\int_{-\infty}^{+\infty} \rho w|\nabla c| F\left(\mathbf{x}-\mathbf{x}^{\prime}\right) d \mathbf{x}^{\prime} \\
& =\int_{-\infty}^{+\infty} \int_{0}^{1} \rho w|\nabla c| \delta\left(c-c^{*}\right) F\left(\mathbf{x}-\mathbf{x}^{\prime}\right) d c^{*} d \mathbf{x}^{\prime} \\
& =\int_{0}^{1}\langle\rho w\rangle_{s}^{*} \Sigma^{*} d c^{*}=\langle\rho w\rangle_{s} \Sigma=\langle\rho w\rangle_{s} \Xi|\nabla \bar{c}|
\end{aligned}
$$

where $\delta$ is Dirac's delta function. $\Sigma^{*}$ is the sub-grid surface density (i.e. the subgrid surface per unit filtering volume) of the $c=c^{*}$ surface and $\langle Q\rangle_{s}^{*}$ denotes the conditional averaging of $Q$ along this surface $\mathrm{c}=c^{*}$. $\Sigma$ and $\langle Q\rangle_{s}$, introduced in Eq. (42) may be viewed as generalized subgrid flame surface density and surface average, respectively, and defined by:

$$
\begin{aligned}
\Sigma & =\int_{0}^{1} \Sigma^{*} d c^{*}=\overline{|\nabla c|} \\
\langle Q\rangle_{s} & =\frac{1}{\Sigma} \int_{0}^{1}\langle Q\rangle_{s}^{*} d c^{*}=\frac{\overline{Q|\nabla c|}}{\Sigma}
\end{aligned}
$$

while $\Xi=\Sigma /|\nabla \bar{c}|$ is the flame front wrinkling factor.

The challenge is now to model $\langle\rho w\rangle_{s}$ and $\Xi$ or $\Sigma$. The first term is related to the internal flame structure while the two others describe the flame / turbulence interaction. Filtered flame models depend on the methods adopted to describe the previous quantities:

- The Boger et al. [106] model relies on the ratio of the surface-averaged mass-weighted displacement speed to the laminar flame speed $S_{L}$ and the fresh gas density $\rho_{u}$ as $\langle\rho w\rangle_{s} \approx \rho_{u} S_{L}$, while $|\nabla \bar{c}|$ is estimated by filtering one-dimensional infinitely thin laminar premixed flame, approximating the result by a progress variable parabolic shape, leading to:

$$
\Sigma=4 \Xi \sqrt{\frac{6}{\pi}} \frac{\widetilde{c}(1-\widetilde{c})}{\Delta}
$$

To ensure a correct sub-grid scale turbulent burning velocity $S_{T}=\Xi S_{L}$ and recover $S_{L}$ when the flame becomes laminar $(\Xi \rightarrow 1)$, Boger and Veynante [107] proposed an adapted model for the unresolved progress variable transport $\bar{\rho}(\widetilde{\mathbf{u}} c-\widetilde{\mathbf{u}} \widetilde{c})$ and solved the filtered progress variable equation:

$$
\frac{\partial \bar{\rho} \widetilde{c}}{\partial t}+\nabla \cdot(\tilde{\rho} \widetilde{\mathbf{u}})=\nabla \cdot\left[\left(\rho_{u} \frac{S_{L} \Xi \Delta}{16 \sqrt{6 / \pi}}\right) \nabla \widetilde{c}\right]+4 \rho_{u} S_{L} \Xi \sqrt{\frac{6}{\pi}} \frac{\widetilde{c}(1-\widetilde{c})}{\Delta}
$$

- Duwig [108] proposed to extract $\langle\rho w\rangle_{s}|\nabla \bar{c}|$ by filtering one-dimensional synthetic laminar flames using a Gaussian expression for the reaction rate.

- F-TACLES model: Fiorina et al. [93] propose to tabulate the unclosed terms by filtering one-dimensional laminar flames derived from detailed chemical simulations, leading to :

$$
\begin{aligned}
-\nabla \cdot[\bar{\rho}(\tilde{\mathbf{u}} c-\widetilde{\mathbf{u}} \widetilde{c})] & =\Xi \Omega_{c}^{F T a b}(\widetilde{c}, \Delta)+(\Xi-1) \nabla \cdot\left(\alpha_{c}^{F T a b}(\widetilde{c}, \Delta) \bar{\rho} \bar{D} \nabla \widetilde{c}\right) \\
\overline{\nabla \cdot(\rho D \nabla c)} & =\nabla \cdot\left(\alpha_{c}^{F T a b}(\widetilde{c}, \Delta) \bar{\rho} \bar{D} \nabla \widetilde{c}\right) \\
\overline{\dot{\omega}}_{c} & =\Xi \dot{\hat{\omega}}_{c}^{F T a b}(\widetilde{c}, \Delta)
\end{aligned}
$$


where the superscript ${ }^{F T a b}$ denotes quantities extracted from one-dimensional filtered laminar premixed flames and tabulated as function of the mass-weighted filtered progress variable $\widetilde{c}$ and the filter size $\Delta . \Omega_{c}^{F T a b}(\widetilde{c}, \Delta)$ corresponds to the unresolved progress variable transport, linked to thermal expansion. Filtered diffusion fluxes and unresolved transport are also modeled from one-dimensional laminar flames, the latter combining thermal transport and a gradient expression estimated from the filtered diffusion fluxes and the wrinkling factor $\Xi$. As both transport and reaction terms are multiplied by the wrinkling factor $\Xi$, such a model predicts a resolved flame propagating at the turbulent flame burning velocity $\Xi S_{L}$, where $S_{L}$ is the laminar flame speed. This model, called F-TACLES (Filtered TAbulated Chemistry for Large Eddy Simulations) is found to provide good results, including detailed chemistry features [93, 109, 110].

Note that the Boger et al. [106] model corresponds to F-TACLES in the limit of infinitely thin premixed flames and where the tabulation is replaced by a parabolic $\widetilde{c}$ function.

\section{Artificially thickened flame model}

Strictly speaking, the Thickened Flame concept for LES is not a filtered flame model but is linked to this family of models through the method used to close unknown terms in the spatially filtered balance equations. The basic idea, proposed in $[111,112]$ for laminar flame calculations, is to consider a flame thicker than the actual one, but having the same laminar burning velocity $S_{L}$. Following simple theories of laminar premixed flame [65], the burning velocity $S_{L}$ and flame thickness $\delta_{L}$ may be expressed as:

$$
S_{L} \propto \sqrt{a \overline{\dot{\omega}}} \quad ; \quad \delta_{L} \propto \frac{a}{S_{L}}
$$

where $a$ is the thermal diffusivity and $\overline{\dot{\omega}}$ the mean reaction rate. Then, an increase of the flame thickness $\delta_{L}$ by a factor $\alpha$ while keeping a constant burning velocity $S_{L}$ is easily achieved by replacing the thermal diffusivity $a$ by $\alpha a$ and the reaction rate $\overline{\dot{\omega}}$ by $\overline{\dot{\omega}} / \alpha$. For sufficiently large $\alpha$ values, the thickened flame front may then be resolved on the LES computational mesh. ${ }^{2}$ The flame thickening concept was demonstrated in an investigation of combustion instabilities leading to flashback [113].

Unfortunately, when the flame is thickened from $\delta_{l}$ to $\alpha \delta_{l}$, the interaction between turbulence and chemistry may be modified because the Damköhler number, $D a=\tau_{t} / \tau_{c}$, comparing turbulent $\left(\tau_{t}\right)$ and chemical $\left(\tau_{c}=S_{L} / \delta_{L}\right)$ time scales is decreased by a factor $\alpha$. This point has been investigated using DNS [114] and an efficiency function, in fact an effective flame wrinkling factor $\Xi$, has been derived to compensate this effect. In practical applications, the thickened flame approach is implemented by changing the diffusivity and the reaction rate $[114,115]$ :

$$
\begin{aligned}
& \text { Diffusivity: } a \longrightarrow \Xi \alpha a \\
& \text { Reaction rate: } \overline{\dot{\omega}} \longrightarrow \Xi \overline{\dot{\omega}} / \alpha
\end{aligned}
$$

This model is then designed to propagate a flame front of thickness $\alpha \delta_{L}$ at the sub-grid scale turbulent burning velocity $\Xi S_{L}$, replacing the flame surface lost in the thickening process by a higher burning velocity.

\footnotetext{
${ }^{2}$ This property of convection/diffusion/reaction balance equations is easily proved by replacing the spatial coordinate $x$ by $x / \alpha$ in the balance equation for a 1D steady propagating flame.
} 
This approach has been successfully used by [116-123], among others. Note also that a dynamic version ${ }^{3}$ of the Thickened Flame Model, where the thickening operation is only applied in the reaction zone to preserve diffusion in non-reacting regions, has also been developed and applied to non-premixed or partially premixed combustion [124]. The thickening factor may also depend on the local grid resolution [120]. Auzillon et al. [109] have compared F-TACLES and TFLES formulations and proposed a relation between filter size $\Delta$ and thickening factor $\alpha$ for a given numerical resolution.

Flame surface wrinkling and flame surface density modeling

While $\langle\rho w\rangle_{s}$ or $\langle\rho w\rangle_{s}|\nabla \bar{c}|$ are extracted from one-dimensional laminar flame analysis, the flame / turbulence interactions is described through a wrinkling factor $\Xi$ or a flame surface density $\Sigma$. These quantities may be deduced from:

- Algebraic expressions, such as, for example, Colin et al. [114] or Charlette et al. [115] expressions or from a fractal analysis [125]. These formulations rely on an equilibrium assumption between flame wrinkling and turbulent fluctuations, which is often not valid for early flame developments.

- Similarity assumptions, taking advantage of the knowledge of resolved scales [126].

- Dynamic modeling where the model parameters entering algebraic expressions are automatically adjusted during the simulation from the known resolved flow field [104, 127-130].

- Balance equations for the flame surface density [106, 131-133] or the wrinkling factor, $\Xi$ [134].

\subsection{Statistical approach}

\subsubsection{Principle}

The statistical formalism is based on probability density functions and is first described here for clarity when thermochemical variables $\varphi$ such as species or temperature depend only on a single variable, for example the mixture fraction $Z$ for infinitely fast chemistry in non-premixed flames. The Favre filtered fuel mass fraction is defined as [135]:

$$
\widetilde{\varphi}(x, t)=\frac{1}{\bar{\rho}} \int_{-\infty}^{+\infty} \rho\left(x^{\prime}, t\right) \varphi\left(Z\left(x^{\prime}, t\right)\right) F\left(x-x^{\prime}\right) d x^{\prime}
$$

Introducing the Dirac $\delta$-function, this expression becomes:

$$
\widetilde{\varphi}(x, t)=\frac{1}{\bar{\rho}} \int_{0}^{1} \int_{-\infty}^{+\infty} \rho(\Psi) \varphi(\Psi) \delta\left(Z\left(x^{\prime}, t\right)-\Psi\right) F\left(x-x^{\prime}\right) d x^{\prime} d \Psi
$$

leading to:

In this expression

$$
\widetilde{\phi}(x, t)=\int_{0}^{1} \phi(\Psi) \widetilde{P}(\Psi, x, t) d \Psi
$$

$$
\widetilde{P}(\Psi, x, t)=\frac{1}{\bar{\rho}} \int_{-\infty}^{+\infty} \rho(\Psi) \delta\left(Z\left(x^{\prime}, t\right)-\Psi\right) F\left(x-x^{\prime}\right) d x^{\prime}
$$

\footnotetext{
${ }^{3}$ The term dynamic might be confusing: it stands here for a local adjustment of the thickening factor to act only in the reaction zone but does not correspond to an automatic adjustment of the model parameters from the known resolved scales as is usually implied in LES.
} 
is the filtered density function (FDF) that may be either presumed or calculated as a solution of a balance equation (see Section 3.2.2). This formulation is easily extended to any thermochemical variable. Mass fractions or reaction rates are then determined as:

$$
\begin{aligned}
\widetilde{\varphi}(x, t)= & \int_{p^{\min }}^{p^{\max }} \int_{T^{\min }}^{T^{\max }} \cdots \int_{0}^{1} \varphi\left(p, T, Y_{1}, Y_{2}, \ldots, Y_{n_{s p}}\right) \\
& \times \widetilde{P}\left(p, T, Y_{1}, Y_{2}, \ldots, Y_{n_{s p}}\right) d P d T d Y_{1} \cdots d Y_{n_{s p}}
\end{aligned}
$$

When the chemistry is tabulated, the previous expression becomes (7):

$$
\begin{aligned}
\tilde{\varphi}(x, t)= & \int_{p^{\min }}^{p^{\max }} \int_{T^{\min }}^{T^{\max }} \cdots \int_{0}^{1} \varphi\left(p, T, \psi_{1}, \psi_{2}, \ldots, \psi_{n}\right) \\
& \times \widetilde{P}\left(p, T, \psi_{1}, \psi_{2}, \ldots, \psi_{n}\right) d P, d T, d \psi_{1}, \cdots, d \psi_{n}
\end{aligned}
$$

The filtered joint probability $\widetilde{P}\left(\psi 1, \psi 2, \cdots, \psi_{n}\right)$ describes the sub-grid scale distribution of thermochemical variables $\psi_{i}$, i.e., in the filtering volume centered on location $x$ at time $t$. Note that flamelet models as devised by Peters $[28,66]$ for non-premixed turbulent flames and based either on infinitely fast chemistry or on solving steady or unsteady systems of Eq. 26, rely on this statistical description and not on the previous geometrical formulation: the flame / turbulence interaction is described through the filtered density function while the flamelet assumption only links the local thermochemical variables correspond to those of laminar flame elements. The challenge is then to determine the filtered density function $\widetilde{P}$.

\subsubsection{Filtered density function $(F D F)$ modeling}

The determination of the FDF is quite similar to what has been exploited in RANS formulations:

Presumed filtered density function Single variable filtered probability density functions are generally modeled using $\beta$-functions, as suggested by Cook and Riley $[136,137]$. These authors also discussed a similarity model to describe the mixture fraction variance without solving an additional balance equation. Olbricht et al. [138] noted that a $\beta$ distribution is expected for temporal statistics but probably not adapted to instantaneous sub-grid scale distributions, suggesting to retain a top-hat function (uniform probability between minimum and maximum parameter values). Also, Fiorina et al. [93] pointed out that a $\beta$ distribution does not behave correctly for laminar premixed flames.

Two variables (progress variable and mixture fraction) or multi-variable (adding, for example, strain rate, initial fresh gas temperature, heat losses, exhaust gas recirculation,... dependencies) filtered probability density functions are modeled assuming statistical independence of parameters. In general, progress variable or mixture fraction distribution are described through $\beta$-functions while other parameters are assumed constant at the sub-grid scale level (Dirac functions). 
FDF transport equation A transport equation for the filtered density function $\widetilde{P}(\Psi, x, t)$ may be derived [135] and reads [139]:

$$
\begin{aligned}
\bar{\rho} \frac{\partial \widetilde{P}}{\partial t}+\tilde{\rho}_{k} \frac{\partial \widetilde{P}}{\partial x_{k}} & =\underbrace{\frac{\partial}{\partial x_{k}}\left[\bar{\rho}\left(\tilde{u}_{k}-\overline{\left(u_{k} \mid \underline{\varphi}=\underline{\Psi}\right)} \tilde{P}\right]\right.}_{\text {Unresolved transport }} \\
& -\underbrace{\bar{\rho} \sum_{i=1}^{N} \frac{\partial}{\partial \Psi_{i}}\left[\overline{\left(\frac{1}{\rho} \frac{\partial}{\partial x_{k}}\left(\mathcal{J}_{i, k}\right) \mid \underline{\varphi}=\underline{\Psi}\right)} \widetilde{P}\right]}_{\text {Molecular diffusion }} \\
& -\underbrace{\bar{\rho} \sum_{i=1}^{N} \frac{\partial}{\partial \Psi_{i}}\left(\frac{1}{\rho} \dot{\omega}_{i}(\underline{\Psi}) \widetilde{P}\right)}_{\text {Chemical reaction }}
\end{aligned}
$$

where $(\overline{Q \mid \underline{\phi}=\underline{\Psi}})$ denotes a conditional averaging of $Q$ for the sampling values $\Psi_{i}$ on the thermochemical variables $\varphi_{i} . \mathcal{J}_{i, k}$ is the $k^{\text {th }}$ component of the diffusion flux of $i^{\text {th }}$ thermochemical variable. The LHS terms and the first RHS term correspond to the resolved and unresolved transport in physical space, respectively, while the last two LHS terms describe the FDF evolution in phase (i.e. $\varphi$ ) space due to molecular diffusion and chemical reaction respectively. Note that the chemical reaction term is closed and need no further modeling. Equation 55 is limited to the composition space (i.e. to the thermochemical variable) but the FDF could also incorporate the velocity components [139].

\subsubsection{Conditional moment closure (CMC) modeling}

The Conditional Moment Closure (CMC) approach, primarily proposed by Klimenko [140] and Bilger [141], (see also [142]), is easily extended to LES, writing filtered scalars as:

$$
\widetilde{\varphi}(\underline{x}, t)=\int_{0}^{1}\left(\overline{\varphi \mid Z^{*} ; \underline{x}, t}\right) \widetilde{P}\left(Z^{*} ; \underline{x}, t\right) d Z^{*}
$$

where $\left(\overline{\varphi \mid Z^{*} ; \underline{x}, t}\right)$ is the filtered conditional mean of $\varphi$ for a given value $Z^{*}$ of the mixture fraction and $\widetilde{P}\left(Z^{*} ; \underline{x}, t\right)$ is the mass-weighted filtered density function of $Z$. In Eq. 56, $\left(\overline{\varphi \mid Z^{*} ; \underline{x}, t}\right)$ describes the filtered chemical flame structure in mixture fraction space and is solution of balance equations. The CMC formalism is classified here as a statistical approach because of the filtered density function $\widetilde{P}\left(Z^{*} ; \underline{x}, t\right)$ entering (56). However, it may also be viewed as a geometrical approach considering multi-surfaces, solving for the filtered conditional mean of $\varphi$ on given iso- $Z^{*}$ surfaces, $\left(\overline{\varphi \mid Z^{*} ; \underline{x}, t}\right)$.

This approach suffers from some drawbacks: it needs a variety of closure schemes, it induces large computational costs (one balance equation per variable $\phi$ and conditional level $Z^{*}$ taken into consideration). It is however conceptually attractive since diffusion flame structures or certain phenomena like autoignition can be directly linked to $Z$-iso surfaces [143]. The CMC approach has been successfully used in some situations [144-147]. 


\subsection{Mixing approach}

The description of reacting flows in terms of turbulent mixing may be based on the extension to LES of simple RANS algebraic models such as the Eddy-Breay-Up or the Eddy-Dissipation-Concept in which chemical reaction rates are assumed to be proportional to the inverse of a mixing time. Following the same concept, sophisticated expressions have been developed to model mixing characteristics based on fractal descriptions of turbulence [148] or partially stirred reactors (PaSR) [149, 150]. A more refined formalism is explored in a series of articles by [151-155] which introduce the Linear Eddy Model (LEM), based on a one-dimensional stochastic description of turbulent stirring processes. In a LES framework, this formulation is used to represent subgrid scale phenomena.

The turbulent stirring mechanism is modeled by a rearrangement process applied to the 1D scalar field. The initial scalar distribution (Fig. 6a) is rearranged on a given segment of size $l$ according to Fig. 6b ("triplet map"). This process may be viewed as the effect of a single turbulent structure of size $l$ located in $x_{0}$. Then, the turbulent mixing is simulated from a stochastic description where vortex locations $x_{0}$, vortex sizes $l\left(l_{k} \leq l \leq \Delta\right.$, where $l_{k}$ is the Kolmogorov length scale and $\Delta$ the LES filter size) and vortex frequencies $\lambda$ are specified according to a given one - dimensional turbulence spectrum.

Molecular diffusion and chemical processes are described by one dimensional balance equations:

$$
\frac{\partial \rho Y_{i}}{\partial t}=\frac{\partial}{\partial x}\left(\rho D_{i} \frac{\partial Y_{i}}{\partial x}\right)+\dot{\omega}_{i}
$$

In summary, the subgrid scale chemical reaction and turbulent mixing are analyzed on the basis of a one dimensional problem which incorporates a simple stochastic description of turbulence. Any detailed chemistry or diffusion features may be easily included in Eq. 57. This approach also provides a direct estimation of filtered mass fractions $\widetilde{Y}_{i}$ or temperature $\widetilde{T}$ without adding additional transport equations for these quantities. Nevertheless, mass fractions and temperature transport between adjacent mesh cells must be modeled. The LEM approach may also be relatively time consuming because a one-dimensional calculation is required in each computational cell.

This approach is probably well suited for large eddy simulations of turbulent mixing [156] and non premixed combustion, at least when combustion phenomena are essentially
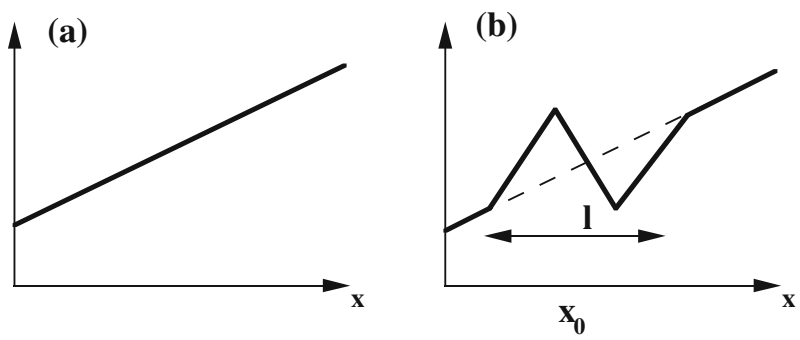

Fig. 6 "Triplet map" used in the Linear Eddy Model developed by Kerstein to simulate a one-dimensional turbulent stirring process. a before mixing; $\mathbf{b}$ simulated mixing by a vortex of size $l$ 
controlled by mixing $[157,158]$. It also has been extended to premixed flames $[159,160]$ and used to compute complex combustion systems such as reverse flow combustor [161]. One-Dimensional Turbulence (ODT) concepts have been used in a different manner in [162] to cope with turbulent premixed flames.

\subsection{Summary}

Table 1 summarizes and classifies turbulent combustion models for large eddy simulations in terms of their primary concepts. Columns cover all existing strategies for chemical descriptions, from fast to detailed chemistry. Rows present the different models derived to account for flame turbulence interactions based on flame surface, statistics or mixing approaches, respectively. Turbulent combustion models appear as combinations between these two primary concepts. Note that some turbulent combustion modeling strategies are adapted to various types of chemical descriptions. For instance, TFLES can be used in practice for single step, reduced or tabulated chemistry.

A particular box in Table 1 does not exhibit all the different features of the models. For example, level-set and flame surface density formalisms were combined with tabulated chemistry but chemical characteristics are generally incorporated in terms of laminar burning velocity, a global quantity and do not explicitly take into account the inner flame structure. The Eddy-Dissipation-Concept (EDC) has been initially devised in the fast chemistry limit [163] and then extended to reduced and detailed chemistries. However, reaction rates are assumed to be inversely proportional to a turbulent mixing time and are bounded by the corresponding reaction rates estimated without turbulence (i.e. computed from Arrhenius laws using filtered thermo-chemical variables), a fairly simple formulation.

The chemical description should be correlated to the flame turbulence interactions modeling. Indeed, the chemical flame structure is affected by strain, curvature, micro-mixing and dilution effects, which are enhanced by turbulence eddies. The challenge for reduced schemes and tabulated chemsitry is therefore to capture such complex flame structure. It motivates the addition of species and reactions or dimensions to chemical mechanisms and chemical look-up tables, respectively.

Table 1 Summary and classification of LES models for reacting flows, in terms of flame / turbulence interaction and chemical descriptions. This classification is based on primary concepts as models may combine several approaches (for example, mixture fraction probability density functions are introduced in flame surface concepts to describe partially premixed combustion). The conditional moment closure (CMC) formalism may be classified as a statistical model, its primary closure scheme, or a multi-surface geometrical approach

\begin{tabular}{|c|c|c|c|c|c|c|}
\hline \multirow{2}{*}{\multicolumn{2}{|c|}{$\begin{array}{l}\text { Primary } \\
\text { concepts }\end{array}$}} & \multicolumn{5}{|c|}{ Chemical description } \\
\hline & & $\begin{array}{c}\text { Fast } \\
\text { chemistry }\end{array}$ & $\begin{array}{l}\text { Single step } \\
\text { chemistry }\end{array}$ & $\begin{array}{l}\text { Tabulated } \\
\text { chemistry }\end{array}$ & $\begin{array}{l}\text { Reduced } \\
\text { schemes }\end{array}$ & $\begin{array}{l}\text { Detailed } \\
\text { chemistry }\end{array}$ \\
\hline \multirow{3}{*}{ 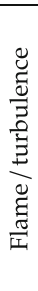 } & $\begin{array}{l}\text { Flame } \\
\text { surface }\end{array}$ & $\begin{array}{l}\text { - Level set } \\
\text { - Boger et al. } \\
\text { - Fractal } \\
\text { - FSD Eq. }\end{array}$ & $\begin{array}{l}\text { - TFLES } \\
\text { - Duwig }\end{array}$ & $\begin{array}{l}\text { - Level set } \\
\text { - Fractal } \\
\text { - FSD Eq. } \\
\text { - TFLES } \\
\text { - F-TACLES }\end{array}$ & $\begin{array}{l}\text { - TFLES } \\
\text { - CMC }\end{array}$ & - CMC \\
\hline & Statistics & - Presumed FDF & - Presumed FDF & $\begin{array}{l}\text { - Presumed FDF } \\
\text { - Transp. FDF }\end{array}$ & $\begin{array}{l}\text { - Transp. FDF } \\
\text { - CMC }\end{array}$ & $\begin{array}{l}\text { - Transp. FDF } \\
\text { - CMC }\end{array}$ \\
\hline & Mixing & - EBU/EDC & $\begin{array}{l}\text {-EDC } \\
\text { - LEM }\end{array}$ & - LEM & $\begin{array}{l}\text {-EDC } \\
\text { - PaSR } \\
\text { - LEM }\end{array}$ & $\begin{array}{l}\text { - EDC } \\
\text { - PaSR } \\
\text { - LEM }\end{array}$ \\
\hline
\end{tabular}


As shown by Veynante and Vervisch [164], flame / turbulence interaction concepts are closely linked: there are exact (but unclosed) relations between flame surface densities, filtered density functions and scalar dissipation rates describing turbulent mixing and filtered reaction rates may be exactly expressed in terms of each of these quantities. For this reason, there is no decisive advantage of a formalism compared to the others, which is not surprising as they only consider the same problem from a different point of view. The only possible benefits lie in the ability to close the unknown terms. In practice, the geometrical approach, based on flame surface area, is well-suited to propagating premixed flames while statistical and mixing concepts are easier to close for flames controlled by turbulent mixing. An important point is to preserve the coherence between flame / turbulence and chemical descriptions. The general temptation, and trend, is to refine as much as possible the chemical description, handling detailed chemical schemes. However most of the expected gains are lost when modeling flame / turbulence interactions through a unique turbulent time scale, usually associated to the filter size $\Delta$. Thus, to expect that relevant results can be obtained by combining a detailed chemical scheme with the EDC concept is likely an illusion.

One should also not forget that each turbulent combustion model has its own requirements in terms of grid resolution and numerical scheme. To draw a comparison between different turbulent combustion model in terms of strong and weak points without considering the entire computational strategy is therefore difficult. In that spirit, comparative studies between LES and experimental data on target flame configurations [165] are regularly carried out in the framework of the International Workshop on Measurement and Computation of Turbulent Flames (TNF)[166]. In particular, results of five LES of the TSF-A flame [165] have been analyzed in a joint publication [167].

\subsection{Comments}

Unresolved scalar fluxes are generally described from a simple gradient assumption. However, DNS analysis have shown that counter-gradient transport may be observed as in RANS, depending on turbulence levels and heat release rates [106]. But, as unresolved LES fluxes are smaller than in RANS, model uncertainties are less influential. Since counter-gradient transport is linked to differential acceleration effects on cold fresh and hot burnt gases, all characteristic length scales are involved. Thereafter, a portion of the counter-gradient phenomena is directly described in large eddy simulations through resolved motions as shown in [107].

Dynamic modeling for turbulent combustion LES gives the opportunity to estimate subgrid scale phenomena from known resolved scales. Dynamic models, where model parameters are automatically adjusted during the computations, have been found to efficiently describe unresolved momentum or scalar transport a possibility which was pioneered by Germano et al. [168]. Up to now, very fews attempts have been made to extend the dynamic formalism to turbulent combustion. They may be classified into two categories. "Indirect" procedures apply the dynamic formalism to the description of the turbulent mixing through variances and scalar dissipation rates of a mixture fraction, an ingredient entering non-premixed combustion models [12, 67, 169-172]. On the other hand, "direct" approaches directly proceed with reaction rates through scale similarity assumptions [173], turbulent flame speed [12, 104] or flame wrinkling factors [115, 127-130, $174,175]$, but concern turbulent premixed flames. Note that aerodynamics and combustion behave differently: most of the flow energy is transported by large scale resolved flow motions, a way to check LES quality [176], while combustion is mainly a subgrid 
scale phenomenon (the flame thickness is generally smaller than the LES grid mesh), potentially leading to an ill-posed problem when looking for a linear parametrization [115]. However, recent results achieved with dynamic models appear to be quite promising [127-130].

\section{Examples of Turbulent Combustion Simulations}

Three examples of practical large eddy simulations including chemistry features are now briefly discussed as illustrations. The first case corresponds to a well-characterized model scale swirling combustor [177]. This configuration is used to compare several global and reduced kinetic schemes and the results are compared in terms of $C O$ mass fractions. The second case presents LES of the Cambridge stratified swirl burner (SwB) [178, 179]. The results shows the influence of heat losses and SGS flame wrinkling models in the context of the Filtered TAbulated Chemistry for LES (F-TACLES). The last case is devoted to MILD (or "flameless") combustion regime where reactants are mixed with burnt gases to reduce flame temperature and the overall nitric oxide emissions.

4.1 Lean partially premixed swirled flame combining reduced/global chemistry and artificially thickened flame model

An interesting configuration for model validation in practical combustion system is the PRECCINSTA swirled burner experimentally investigated in [177]. The geometry is representative to a certain extent of an actual aeronautical combustion device. It comprises a plenum, a swirl-injector and a combustion chamber. Figure 7 shows the combustion chamber geometry and the axial positions where detailed measurements are available (velocity, temperature and major species mass fractions) [177]. This well-characterized configuration is a target test case for modeling strategies adapted to practical combustors. Roux et al. [3] first performed simulations combining the thickened flame model with a two-step chemical mechanism. Moureau et al. [180] validated a new level-set algorithm to track the flame front position in this configuration. Galpin et al. [82] coupled a thermo-chemical look-up table with the filtered flow equations through a presumed $\beta$-FDF. This configuration was also retained to validate the F-TACLES model described previously [93, 181].

Franzelli et al. [182] present simulations of stable operating conditions with a global equivalence ratio $\phi=0.83$. It provides a nice illustration of the importance of the chemical modeling on the mean turbulent flame structure. The turbulence / chemistry interaction is represented by the thickened flame model, TFLES (Section 3.1.2). Six chemical mechanisms for methane/air flames, with increasing complexity, are tested: the two-step fitted schemes 2S_CH4_BFER and 2S_CH4_BFER* (adjusted to account for strain rate effects) developed by Franzelli et al. [23], the four-step schemes developed by Jones and Lindstedt [183] (referred here as JONES), Peters [184], Seshadri [185] and the detailed mechanism proposed by Lu [186]. Principal chemical scheme characteristics are summarized in Table 2. Figure 8 compares the experimental and the numerical temperature fields obtained using the six chemical schemes. Although the overall agreement is acceptable, non-negligible differences are observed between chemical models. The consumption speed is overestimated by 2S_CH4_BFER and JONES mechanisms, leading to shorter flames than in the experiment. The modified 2S_CH4_BFER* scheme, capturing the impact of strain rates, predicts a longer flame than the 2S_CH4_BFER mechanism while the analytical schemes (PETERS, SESHADRI) correctly retrieve the flame length. 


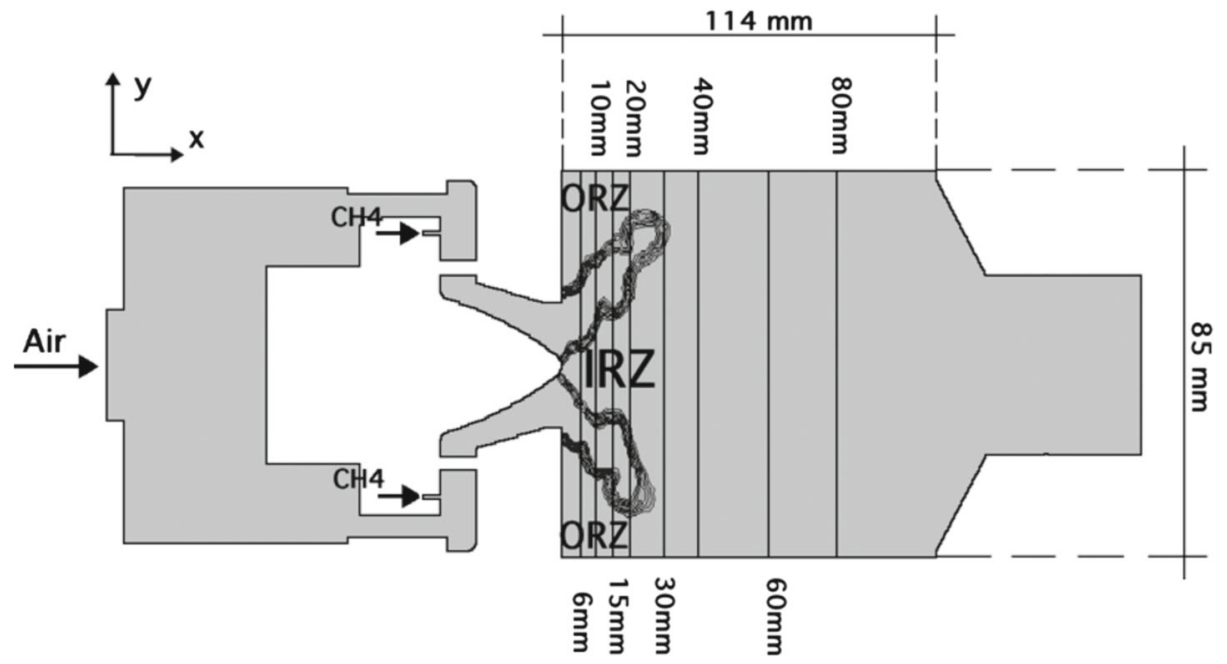

Fig. 7 PRECCINSTA injection system. Dashed lines shows the axial positions where detailed measurements are available

Figure 9 compare predicted mean $\mathrm{CO}$ mass fraction profiles to experimental data (note that experimental uncertainties on $C O$ was estimated to be of the order of $50 \%$ ). For the sake of clarity, 2S_CH4_BFER, 2S_CH4_BFER* and JONES results are displayed at the top in black while the analytical schemes (PETERS and SESHADRI) are shown at the bottom in grey. The simplest 2S_CH4_BFER and 2S_CH4_BFER* schemes notably underestimate $\mathrm{CO}$ mass fractions in the reaction zone but recover the correct level at equilibrium $(h=60$ $\mathrm{mm}$ ). In contrast, the JONES mechanism overestimates maximum values of mean CO mass fractions in the reaction zone as expected from the laminar analysis. Only the analytical schemes (PETERS, SESHADRI) provide fair predictions of CO mass fractions.

4.2 Simulation of a turbulent flame stabilized by heat losses combining premixed flamelet tabulated chemistry and flame filtering.

The Cambridge stratified swirl burner ( $\mathrm{SwB}$ ) geometry, consists of two concentric tubes surrounding a central bluff-body $[178,179]$. The inner and outer methane-air streams inlets

Table 2 Chemical scheme characteristics

\begin{tabular}{lll}
\hline Name & $\begin{array}{l}\text { Number } \\
\text { of species }\end{array}$ & $\begin{array}{l}\text { Number } \\
\text { of reactions }\end{array}$ \\
\hline 2S_CH4_BFER [23] & 6 & 2 \\
2S_CH4_BFER* [23] & 6 & 2 \\
JONES [183] & 7 & 4 \\
PETERS [184] & 8 & 4 \\
SESHADRI [185] & 8 & 4 \\
LU [186] & 13 & 73 \\
\hline
\end{tabular}



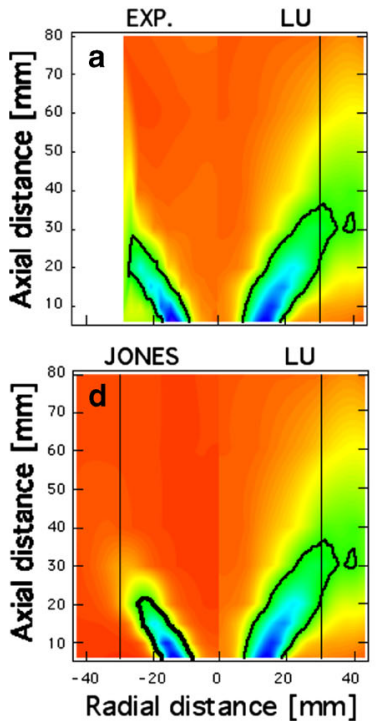
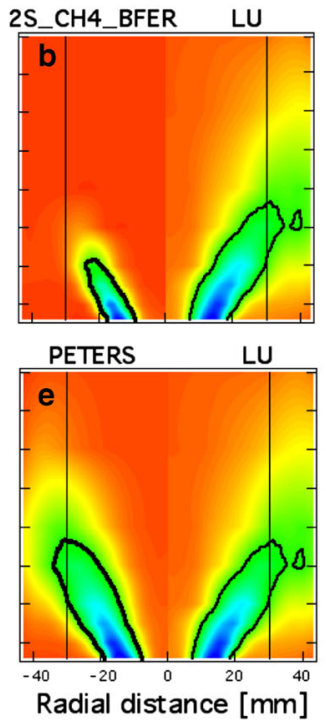
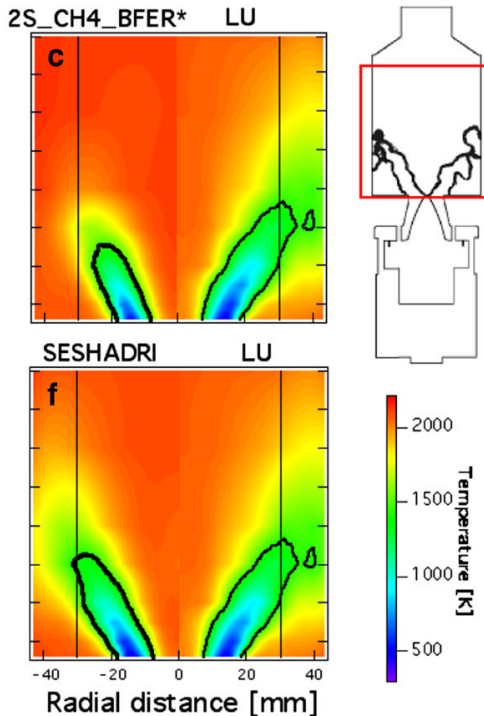

Fig. 8 Mean temperature field in the vertical mid-plane. Comparison between experiments and the kinetic schemes indicated in Table 2. Numerical data are from [182]

are controlled independently in terms of bulk velocity and equivalence ratio. A surrounding air co-flow isolates the flame from ambient perturbations. A wide range of operating conditions have been experimentally investigated by varying the degree of stratification and swirl. Experimental data available include velocity, temperature and local equivalence ratio [178, 179]. Recent measurements of the bluff-body wall temperature using phosphor thermometry [187] evidences the importance of heat transfer from burnt gases to the system boundaries. Experimental campaigns reveal that the flame structure is influenced by fuel stratification, turbulence and heat losses.

Mercier et al. [188] have recently performed numerical simulations of the Cambridge burner using the F-TACLES formalism. The turbulent combustion model, which combines premixed flamelet tabulation and flame filtering, propagates the resolved flame front at the sub-grid scale turbulent burning velocity $S_{T, \Delta}[36,110]$ :

$$
\rho_{0} S_{T, \Delta}=\Xi_{\Delta \gamma} \int_{0}^{1} \rho_{0} S_{l}^{a d}\left(Z^{\prime}\right) P\left(Z^{\prime}\right) d Z^{\prime},
$$

where $S_{l}^{a d}(Z)$ is the consumption speed of a freely propagating adiabatic laminar premixed flame within fresh gases of mixture fraction $Z, \Xi_{\Delta}$ the sub grid scale flame front wrinkling factor, measuring the sub-grid scale flame surface and $\gamma$ a coefficient accounting for heat losses [36]. $\widetilde{P}(Z)$ is the mixture fraction Filtered Density Function (FDF). Sub-models for quantities $\gamma$ (heat losses), $\widetilde{P}(Z)$ (SGS fuel stratification) and $\Xi_{\Delta}$ (SGS flame wrinkling) are required to close Eq. 58. The sensitivity to these sub-models is investigated in [188] through the simulations of the non-swirling premixed (SwB1) and stratified (SwB5) flames. In this study $\gamma$ is modeled from the consumption speed of burner-stabilized flame [36], $\widetilde{P}(Z)$ is presumed by a $\beta$-function [110] and the subgrid scale flame wrinkling is described by an analytical expression [115].

Simulations first indicated that heat losses drastically decrease the flame consumption speed at the flame basis. Figure 10 compares two instantaneous views of the filtered 
Fig. 9 Mean $C O$ mass fraction profiles at five axial position shown in Fig. 7. The

experimental (o) and LU (ם) results are compared to numerical results Top: 2S_CH4_BFER (solid), 2S_CH4_BFER*(dashed) and JONES (dotted); bottom: PETERS (line) and SESHADRI (dashed). Data from [182]

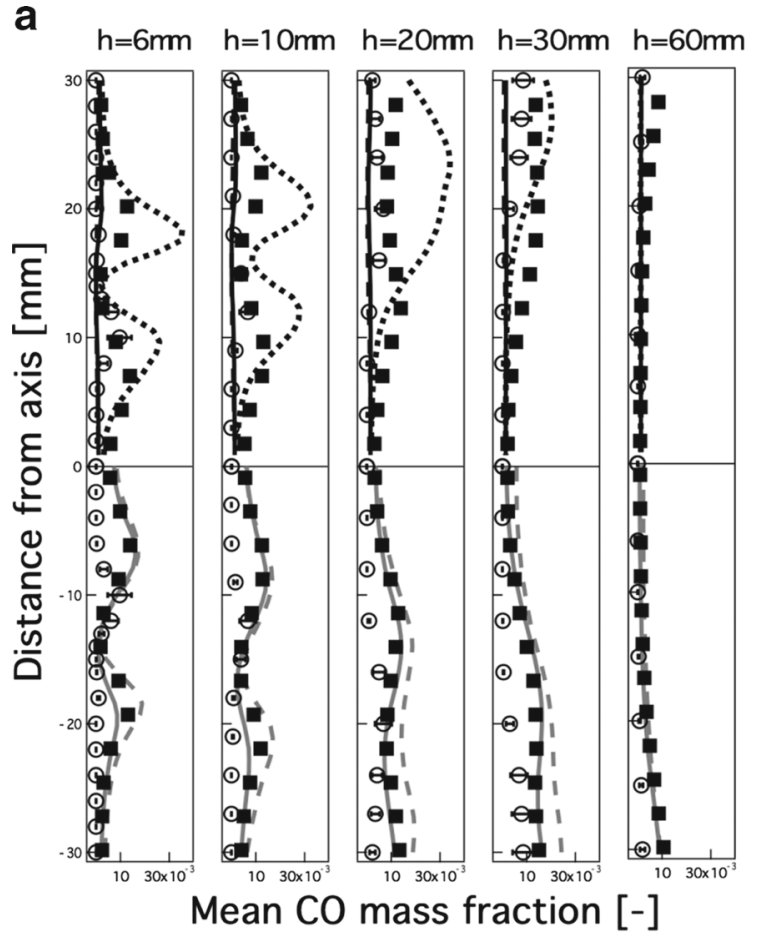

b

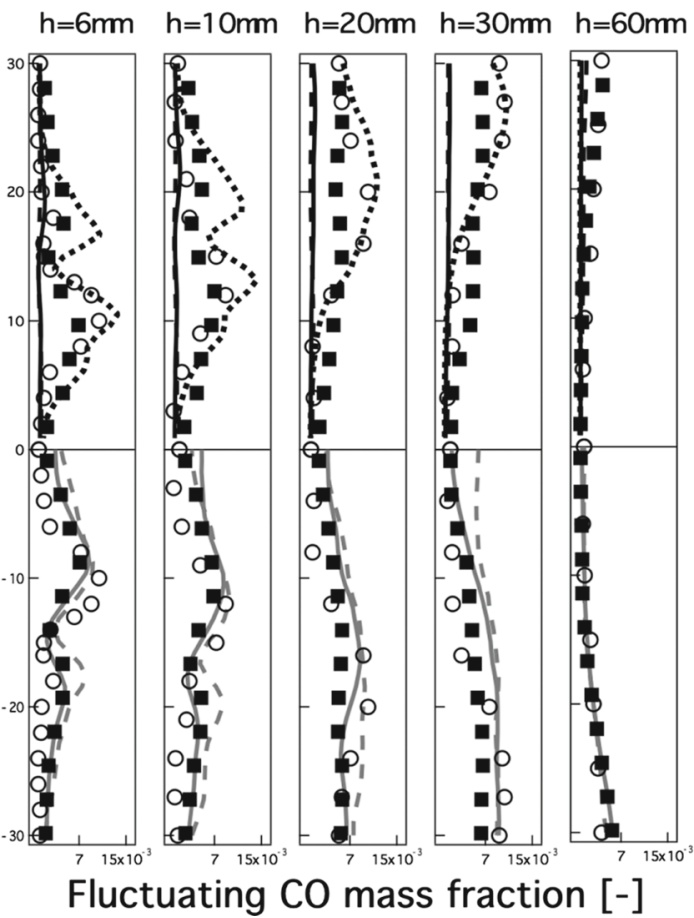




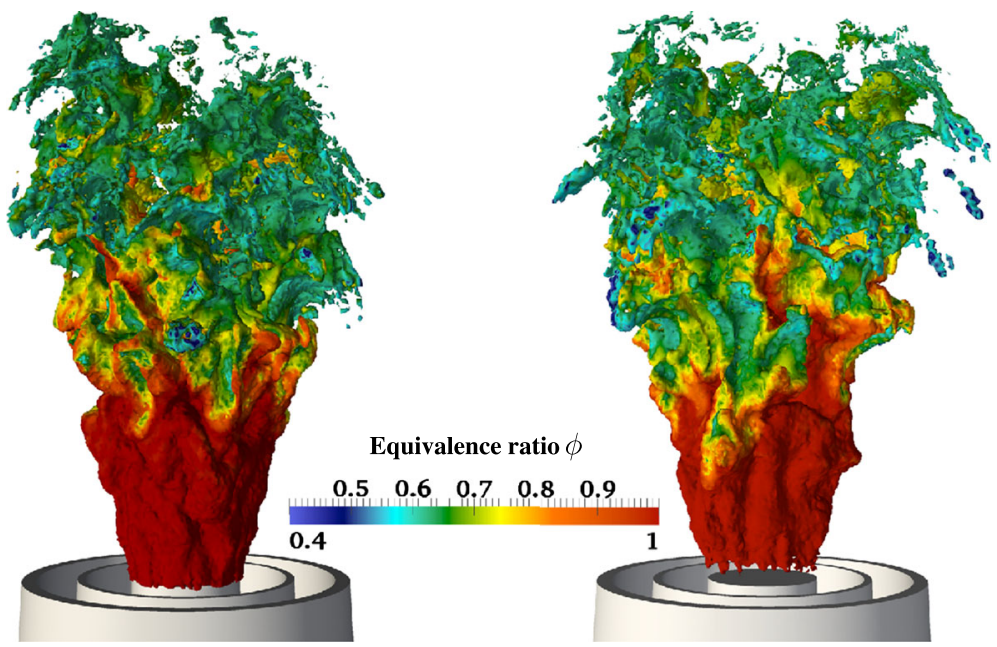

Fig. 10 Iso-surface of filtered progress variable reaction rate $\bar{\rho} \widetilde{\tilde{\omega}}_{Y_{c}}$ colored by fresh gas equivalence ratio $\phi$ for the stratified (SwB5) case. Left: Adiabatic computation. Right: Non-adiabatic computation

progress variable reaction rate iso-surface extracted from adiabatic and non-adiabatic simulations of the SwB5 case. The flame is anchored on the burner bluff-body for adiabatic conditions while the non-adiabatic simulation predicts a lifted flame. Indeed, heat losses affect the flow enthalpy and influence the filtered flame propagation speed through the factor $\gamma(58)$.

A second finding is that constants involved in SGS wrinkling models have a great impact on the mean flame brush position. The $\Xi_{\Delta}$ models sensitivity analysis shows that the saturated formulation of the Charlette et al. [115] model with a static estimation of the $\beta$ parameter is too rough to capture different flame wrinkling regimes observed in the

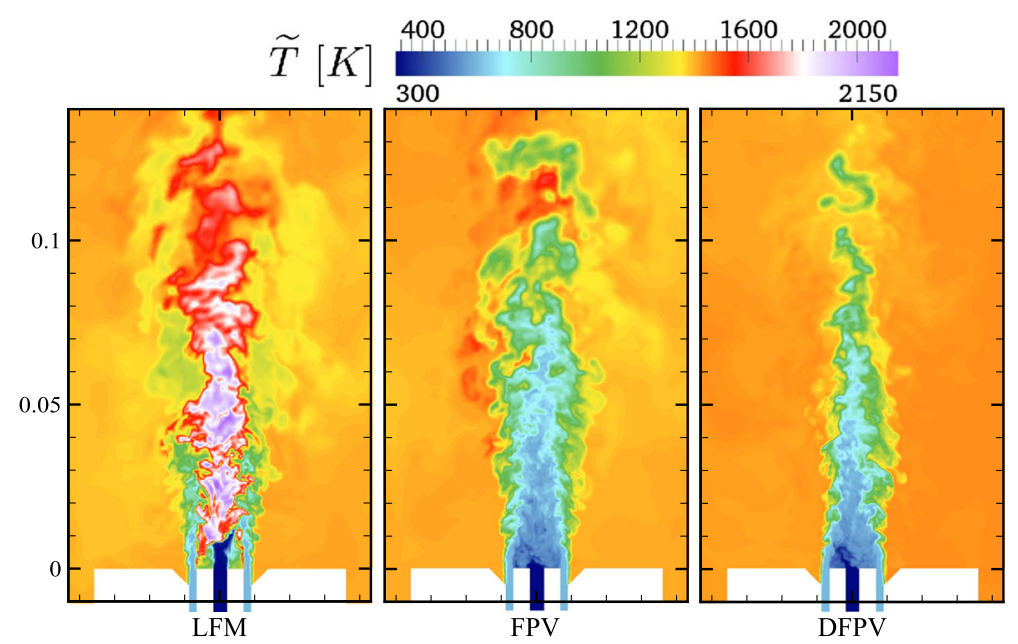

Fig. 11 Temperature fields in a median plan for the three models. The view focus on the injection system. Spatial dimensions are given in meters. left: LFM model; middle: FPV model; right: DFPV model. From [39] 
Fig. 12 Time-averaged temperature (top) and dry mole fractions of $\mathrm{CO}$ (bottom) along the centerline of the configuration. symbols: experimental data points; continuous line: DFPV model; dashed line: FPV model; dashed-dot-dot line: LFM model. From [39]
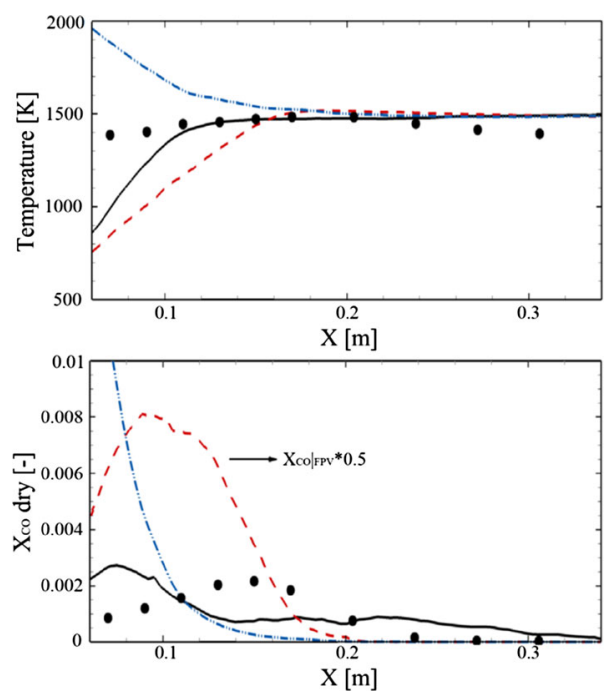

SwB configuration. The Charlette et al. [115] and Colin et al. [114] models are theoretically attractive since they are designed to degenerate correctly towards the laminar burning regime but they are also sensitive to model parameters such as the SGS velocity fluctuations $u_{\triangle}^{\prime}$. Finally, the dynamic formulation $[127,128]$ is sufficiently flexible to capture the flame brush position over the whole computational domain.

4.3 Simulation of a MILD combustor combining chemistry tabulated from non-premixed flamelets and presumed FDF

The thermal efficiency of combustion systems can be increased by transferring heat from exhaust products to fresh gases by means of regenerative heating. Unfortunately, the increase of the reactant temperature tends to promote the nitric oxide $\left(\mathrm{NO}_{x}\right)$ formation. A solution to control and reduce peak flame temperature is to operate the burner in the MILD (Moderate or Intense Low-oxygen Dilution) combustion regime [37]. A major issue to model MILD combustion is the pronounced sensitivity of the flame structure to the reaction chemistry.

These issues are illustrated by examining the configuration designed and experimented by Castela et al. [189]. A reversed flow combustion chamber, where inlet and exhaust ports are located on the same side, ensures sufficiently large residence times to complete combustion and promote intense mixing of burned gases with reactants. The injection system combines a central natural gas injection ( $4 \mathrm{~mm}$ diameter) and a surrounding annular jet for preheated $(600 \mathrm{~K})$ air.

Assuming a priori a non premixed flame structure, Lamouroux et al. [39] tabulated the chemistry from diffusion flamelet trajectories. Three chemistry tabulation techniques presented in Section 2.3.3 are considered: Steady Strained Flamelet Model (S-SFM), Steady-Flamelet Progress Variable (S-FPV) and Diluted Flamelet Progress Variable (DFPV). A statistical description is retained for combustion / turbulence interaction. A $\beta$-FDF models mixture fraction statistics while Dirac $\delta$-functions are chosen to represent the other chemical look-up table coordinate distributions. The three modeling strategies have been 
implemented in the finite-volume low Mach number code YALES2 [9]. Details on models and numerical simulations are given in [39].

Instantaneous temperature fields are compared in Fig. 11. S-LFM predicts considerably higher temperatures than the other two models. As S-LFM excludes flame extinction, the maximum temperature is close to the adiabatic temperature of $2150 \mathrm{~K}$. The FPV approach allows the existence of unburned mixtures as solutions of the flamelet equations. It therefore predicts a lower maximum temperature (Fig. 11, middle). The D-FPV model (Fig. 11, right), exhibits qualitative similarities with the temperature field predicted by the FPV-model. However a detachment of the reaction zone from the region between air and fuel inlets as well as a lower temperature field, compared to the two other simulations, is observed. Because of the effect of dilution on the combustion process, the penetration length of the reactants is lower in the D-FPV model than in the FPV model.

Time-averaged temperature profiles along the burner centerline are compared in Fig. 12 (top). The LFM model overestimated temperatures until $170 \mathrm{~mm}$. The FPV model predicts a lower heat-release rate in the nozzle near-field, and good agreement with experimental data is obtained for $x>150 \mathrm{~mm}$, corresponding to $\sim 44 \%$ of the total length of the combustion chamber. A noticeable improvement is obtained with the DFPV model which reproduces the temperature homogeneity in a better way. Figure 12 (bottom) compares averaged carbon monoxide mole fractions along the centerline. Large differences are observed between the three model predictions. The LFM model predicts a fast chemistry for all equivalence ratios, which leads to a rapid increase of $\mathrm{CO}$ in the nozzle-near region, followed by a rapid consumption of $\mathrm{CO}$ due to the relaxation towards equilibrium. The delayed combustion process predicted by the FPV model leads to an over-prediction of CO, since the chemistry does not include specificities in chemical reactions due to the mixing with hot burned gases. In contrast, when the dilution of reactants is taken into account, the prediction of experimentally reported CO-profiles is improved. Despite the high number of dimensions in the look-up table (five for D-FPV), significant differences between the simulation and the measurements are still observed.

\section{Conclusions}

The problem of turbulent combustion has posed an essential challenge to scientists working in this field but substantial progress has been accomplished with the development of numerical simulations. Much progress results from a better understanding of the fundamental processes in combination with improved models and advanced numerical simulation tools. Advances in computational performance and the availability of large scale computer power have allowed a rapid development of large eddy simulation of combustion. Large eddy simulation constitutes a considerable improvement with respect to the more standard Reynolds Averaged Navier-Stokes (RANS) equations which has prevailed for many years and is still widely used in engineering applications. LES is specifically useful in combustion because it yields a realistic description of the flame on a large scale, offers a better description of the flame / turbulence interactions (often described through a single turbulent time in RANS), provides the spatial location of fresh and burnt gases and naturally contains the history of the flow from the injector to the exhaust. These features are extremely useful to analyze dynamical phenomena like ignition, propagation, lean blow out or instabilities. One central issue which constitutes the focal point of this review is that of the interaction between the detailed chemistry and the turbulent flow field. It is not possible to use a full kinetic scheme in such large scale calculations because this would require to solve an excessively 
large number of equations describing the intermediate species involved. The direct integration of these equations would also not provide a suitable account of the interactions with turbulence. There are better ways to deal with this problem as explained in this article. One method which has been found to be practical and suitable relies on chemistry tabulation.In this formulation it is assumed that a turbulent flame is composed of an ensemble of generic laminar flame elements. Many problems can be treated in this manner, but this assumption inudces two major limitations. First, the identification of the combustion elements representative of the overall turbulent chemical flame structure is not always obvious. The use of single flamelet archetypes allows to capture the chemical structure of well-identified flames (such as purely premixed flames or diffusion flames) but introduces biases in the prediction of the chemical structure of more complex situations. More coordinates have to be added to the look-up table to capture the complex flame structures developing in reactive flows. The introduction of these coordinates requires additional modeling assumptions that increase the complexity of the methodology and raise questions with regard to its relevance for the simulations of industrial devices. The second limitation comes from the assumption that the inner structure of the turbulent flame front is close to that of a laminar flame. This assumption, valid for some conventional combustors, becomes questionable for example for low temperature flames.

Alternatively, one might try to incorporate complex chemistry in LES by taking full advantage of recent progress in super computing and represent reactive paths by skeletal mechanisms. This could provide enough flexibility to capture the variety of chemical structures arising in industrial combustion systems but would also require novel modeling routes for closing the filtered species balance equations.

Acknowledgments It is a pleasure to acknowledge many helpful discussions with our colleagues Nasser Darabiha, Olivier Gicquel, Thomas Schmitt and Ronan Vicquelin and to thank Benedetta Franzelli, Pierre Auzillon, Jean Lamouroux and Renaud Mercier for some of the material included in this article. YALES2 and AVBP flow solvers were made available to us through the GIS Success. Computational resources were provided by GENCI.

\section{References}

1. Key world energy statistics 2014: Technical report, International Energy Agency (2013)

2. Poinsot, T., Veynante, D. Theoretical and numerical combustion, 3rd edn. T. Poinsot (2011)

3. Roux, S., Lartigue, G., Poinsot, T., Meier, U., Berat, C.: Combust. and Flame 141(1-2), 40 (2005)

4. Smith, G.P., Golden, D.M., Frenklach, M., Moriarty, N.W., Eiteneer, B., Goldenberg, M., Bowman, C.T., Hanson, R.K., Song, S., Gardiner, W.C., Lissianski, V.V., Qin, Z.: www.me.berkeley.edu (1999)

5. Dagaut, P., Cathonnet, M.: Prog. Energy Combust. Sci. 32, 48 (2006)

6. Mizobuchi, Y., Tachibana, S., Shinjo, J., Ogawa, S., Takeno, T.: In: The proceedings of the twentyninth symposium (International) on combustion, pp. 2009-2015. The Combustion Institute, Pittsburgh (2002)

7. Bell, J.B., Day, M.S., Shepherd, I.G., Johnson, M.R., Cheng, R.K., Grcar, J.F., Beckner, V.E., Lijewski, M.J.: PNAS 102, 10006 (2005)

8. Moureau, V., Domingo, P., Vervisch, L.: C. R. Mecanique 339, 141 (2011)

9. Moureau, V., Domingo, P., Vervisch, L.: From large-eddy simulation to direct numerical simulation of a lean premixed swirl flame: Filtered laminar flame-pdf. Combust. Flame 158(7), 1340 (2011)

10. Chen, J.H.: Proc. Combust. Inst. 33(1), 99 (2011)

11. Janicka, J., Sadiki, A.: Proc. Combust. Inst. 30(1), 537 (2005)

12. Pitsch, H.: Annu. Rev. Fluid Mech. 38, 453 (2006)

13. Gicquel, L., Staffelbach, G., Poinsot, T.: Prog. Energy Combust. Sci. 38(6), 782 (2012)

14. Maas, U., Pope, S.: Combust. Flame 88, 239 (1992)

15. Bhattacharjee, B., Schwer, D.A., Barton, P.I., Green, W.H.: Combust. and Flame 135(3), 191 (2003)

16. Lu, T., Law, C.K.: Proc. Combust. Inst. 30, 1333 (2005) 
17. Pepiot-Desjardins, P., Pitsch, H.: Combust. Flame 154(67-81) (2008)

18. Valorani, M., Creta, F., Donato, F., Najm, H.N., Goussis, D.A.: Proc. Combust. Inst. 31, 483 (2007)

19. Goussis, D.A., Maas, U.: In: Echekki, T., Mastorakos, E. (eds.) Turbulent combustion modeling, Fluid Mechanics and Its Applications, vol. 2011, pp. 193-220. Springer Dordrecht Heidelberg London New York (2011)

20. Westbrook, C., Dryer, F.: Combust. Sci. Technol. 27, 31 (1981)

21. Fernández-Tarrazo, E., Sánchez, A.L., Liñán, A., Williams, F.A.: Combust. Flame 147(1-2), 32 (2006)

22. Boudier, G., Gicquel, L., Poinsot, T., Bissieres, D., Bérat, C.: Combust. Flame 155, 196 (2008)

23. Franzelli, B., Riber, E., Sanjosé, M., Poinsot, T.: Combust. and Flame 157(7), 1364 (2010)

24. Abou-Taouk, A., Sigfrid, I., Ronald, W., Eriksson, L.E.: Turbul. Heat Mass Transfer 7(7), 785 (2012)

25. Farcy, B., Abou-Taouk, A., Vervisch, L., Domingo, P., Perret, N.: Fuel 118(0), 291 (2014)

26. Pope, S.B.: Proc. Combust. Inst. 34(1), 1 (2013)

27. Gicquel, O., Thévenin, D., Hilka, M., Darabiha, N.: Combust. Theory Model. 3, 479 (1999)

28. Peters, N.: Prog. Energy Combustion. Sci. 10, 319 (1984)

29. Bradley, D., Kwa, L.K., Lau, A.K.C., Missaghi, M.: L Combust. Flame 71, 109 (1988)

30. Masri, A., Bilger, R., Dibble, R.: Combust. Flame 73, 261 (1988)

31. Regele, J.D., Knudsen, E., Pitsch, H., Blanquart, G.: Combust. and Flame 160(2), 240 (2013)

32. Verhoeven, L., Ramaekers, W., van Oijen, J., de Goey, L.: Combustion and Flame 159(1), 230 (2012)

33. Maragkos, G., Rauwoens, P., Merci, B.: Combust. Flame 160(9), 1903 (2013)

34. Pitsch, H., Peters, N.: Combust. Flame 114, 26 (1998)

35. Sutherland, J.C., Smith, P.J., Chen, J.H.: Combust. Theory Model. 9(2), 365 (2005)

36. Mercier, R., Auzillon, P., Moureau, V., Darabiha, N., Gicquel, O., Veynante, D., Fiorina, B.: Flow Turb. and Comb. 93(2), 349 (2014)

37. Cavaliere, A., de Joannon, M.: Prog. Energy Combust. Sci. 30(4), 329 (2004)

38. Ihme, M., See, Y.C.: Proc. Combust. Inst. 33(1), 1309 (2011)

39. Lamouroux, J., Ihme, M., Fiorina, B., Gicquel, O.: Combust. Flame 161(8), 2120 (2014)

40. Hasse, C., Peters, N.: Proc. Combust. Inst. 30, 2755 (2005)

41. Naudin, A., Fiorina, B., Paubel, X., Veynante, D., Vervisch, L.: In: Proceedings of the summer program, Center For Turbulence Research, Stanford University (2006)

42. Ihme, M., Shunn, L., Zhang, J.: J. Comput. Phys. 231(23), 7715 (2012)

43. Niu, Y.S., Vervisch, L., Tao, P.D.: Combust. and Flame 160(4), 776 (2013)

44. Fiorina, B., Baron, R., Gicquel, O., Thévenin, D., Carpentier, S., Darabiha, N.: Combust. Theor. Modell. 7, 449 (2003)

45. Moss, J.B., Bray, K.: Acta Astronaut. 4, 291 (1977)

46. Embouazza, M.: Etude de l'auto-allumage par réduction des schémas cinétiques chimiques. Application à la combustion homogène diesel. Ph.D. Thesis, Ecole Centrale Paris (2005)

47. Galpin, J., Angelberger, C., Naudin, A., Vervisch, L.: J. Turbul. 9(13), 1 (2008)

48. Vicquelin, R.: Tabulation de la cinétique chimique pour la modélisation et la simulation de la combustion turbulente. Ph.D. Thesis, Ecole Centrale Paris (2010)

49. Tudorache, D., Auzillon, P., Gicquel, O., Darabiha, N., Fiorina, B.enoit.: In: 23th ICDERS, Irvine (2011)

50. van Oijen, J.A., de Goey, L.P.H.: Proceedings of the European Combustion Meeting (2009)

51. Godel, G., Domingo, P., Vervisch, L.: Proc. Combust. Inst. 32(1), 1555 (2009)

52. Ihme, M., Pitsch, H.: Phys. Fluids 20(5), 055110 (2008)

53. Pecquery, F., Moureau, V., Vervisch, L.: Combust. Flame 161(2), 496 (2014)

54. Lam, S.H., Goussis, D.A.: In: Proceedings of the 22nd Symposium (International) on combustion, pp. 931-941. The Combustion institute, Pittsburgh (1988)

55. Colin, O., da Cruz, A.P., Jay, S.: Proc. Combust. Inst. 30(2), 2649 (2005)

56. Jay, S., Colin, O.: Proc. Combust. Inst. 33(2), 3065 (2011)

57. Bradley, D., Gaskell, P.H., Gu, X.J.: In: The proceedings of the twenty-seventh symposium (International) on combustion, pp. 1199-1206. The Combustion Institute, Pittsburgh (1998)

58. Gicquel, O., Darabiha, N., Thévenin, D.: Proc. Combust. Inst. 28, 1901 (2000)

59. Kee, R.J., Grcar, J.F., Smooke, M.D., Miller, J.A.: A fortran program for modelling steady laminar onedimensional premixed flames. Technical Report SAND85-8240-UC-401, Sandia National Laboratories (1985)

60. Godwin, D.: http://www2.galcit.caltech.edu/edl/public/chemkin.html

61. Lindstedt, P.: 12 month progree report 1. Technical report, Brite Euram Program Project BE 951523. Report No. TR-96 009 (1997)

62. van Oijen, J.A., Lammers, F.A., de Goey, L.P.H.: Combust. Flame 127(3), 2124 (2001) 
63. Fiorina, B., Gicquel, O., Vervisch, L., Carpentier, S., Darabiha, N.: Combust. Flame 140(3), 147 (2005)

64. Ramaekers, W.J.S., van Oijen, J.A., de Goey, L.P.H.: Flow, Turbul. Combust. 84(3), 1386 (2010)

65. Williams, F.A.: Combustion Theory. The Fundamental Theory of Chemically Reacting Systems, 2nd edn. Benjamin/Cummings, Menlo Park (1985)

66. Peters, N.: Turbulent Combustion. Cambridge University Press, Cambridge (2000)

67. Pierce, C., Moin, P.: J. Fluid Mech. 504, 73 (2004)

68. Michel, J.B., Colin, O., Veynante, D.: Combust. Flame 152(1-2), 80 (2008)

69. Ihme, M., See, Y.C.: Combust. Flame 157(10) (2010)

70. Delhaye, S., Somers, L., van Oijen, J., de Goey, L.: Combust. Flame 155(1-2), 133 (2008)

71. Delhaye, S., Somers, L., van Oijen, J., de Goey, L.: Proc. Combust. Inst. 32(1), 1051 (2009)

72. Vreman, A., Albrecht, B., van Oijen, J., de Goey, L., Bastiaans, R.: Combust. Flame 153(3), 394 (2008)

73. Bekdemir, C., Somers, L., de Goey, L., Tillou, J., Angelberger, C.: Proc. Combust. Inst. 34(2), 3067 (2013)

74. Bekdemir, C., Somers, B., de Goey, P.: Combust. Flame 161(1), 210 (2014)

75. Bykov, V., Maas, U.: Combust. Theor. Modell. 11(6), 839 (2007)

76. Bykov, V., Maas, U.: Proc. Combust. Inst. Part 32(1), 561 (2009)

77. Nguyen, P., Vervisch, L., Subramanian, V., Domingo, P.: Combust. Flame 157(1), 43 (2010)

78. Franzelli, B., Fiorina, B., Darabiha, N.: Proc. Combust. Inst. 34(1), 1659-1666 (2013)

79. de Swart, J.A.M., Bastiaans, R.J.M., van Oijen, J.A., de Goey, L.P.H., Cant, R.S.: Flow, Turbul. Combust. 85, 473 (2010)

80. Vreman, A., van Oijen, J., de Goey, L., Bastiaans, R.: Int. J. Hydrogen Energy 34(6), 2778 (2009)

81. Nambully, S., Domingo, P., Moureau, V., Vervisch, L.: Combust. Flame 161(7), 1756 (2014)

82. Galpin, J., Naudin, A., Vervisch, L., Angelberger, C., Colin, O., Domingo, P.: Combust. Flame 155, 247 (2008)

83. Vicquelin, R., Fiorina, B., Payet, S., Darabiha, N., Gicquel, O.: Proc. Combust. Inst. 33 33(1), 1481 (2011)

84. Poinsot, T., Lele, S.K.: J. Comput. Phys. 1(101), 104 (1992)

85. Pope, S.B.: Combust. Theory Model. 1, 41 (1997)

86. Flemming, F., Sadiki, A., Janicka, J.: Prog. Comput. Fluid Dyn. 5(7), 375 (2005)

87. Ihme, M., Marsen, A.L., Pitsch, H.: J. Neural Comput. 20, 1 (2007)

88. Ribert, G., Gicquel, O., Veynante, D., Darabiha, N.: Combust. Flame 146, 649 (2006)

89. Ribert, G., Wang, K., Vervisch, L.: Fuel 91(1), 87 (2012)

90. Veynante, D., Fiorina, B., Domingo, P., Vervisch, L.: Combustion Theory and Modelling. In Press (2008)

91. Fiorina, B., Gicquel, O., Veynante, D.: Proc. Combust. Inst. 32(2), 1687 (2009)

92. Weise, S., Messig, D., Meyer, B., Hasse, C.: Combust. Theory Model. 17(3), 411 (2013)

93. Fiorina, B., Vicquelin, R., Auzillon, P., Darabiha, N., Gicquel, O., Veynante, D.: Combust. Flame 157, 465 (2010)

94. Pitsch, H., Duchamp de la Geneste, L.: Proc. Comb. Institute 29, 2001 (2002)

95. Kerstein, A., Ashurst, W., Williams, F.: Phys. Rev. A 37(7), 2728 (1988)

96. Piana, J., Veynante, D., Candel, S., Poinsot, T.: In: Chollet, J., Voke, P., Kleiser, L. (eds.) In: Direct and large eddy simulation II, pp. 321-330. Kluwer Academic Publishers, Dordrecht, The Netherlands (1997)

97. Moureau, V., Fiorina, B., Pitsch, H.: Combust. Flame 156(4), 801 (2009)

98. Knudsen, E., Kim, S.H., Pitsch, H.: Phys. Fluids 22(11) (2010)

99. Menon, S., Jou, W.: Combust. Sci. Technol. 75, 53 (1991)

100. Schmidt, H., Klein, R.: Comb. Theory Model. 7(2), 243 (2003)

101. Pitsch, H.: Combust. Flame 143(4), 587 (2005)

102. Wang, P., Bai, X.: Proc. Comb. Inst. 30, 583 (2005)

103. Dahms, R., Peters, N., Stanton, D.W., Tan, Z., Ewald, J.: Int. J. Engine Research 9(1), 1 (2008)

104. Knudsen, E., Pitsch, H.: Combust. Flame 154, 740 (2008)

105. Schneider, E., Maltsev, A., Sadiki, A., Janicka, J.: Combust. Flame 152(4), 548 (2008)

106. Boger, M., Veynante, D., Boughanem, H., Trouvé, A.: In: 27th symposium (International) on combustion, pp. 917-925. The Combustion Institute, Pittsburgh (1998)

107. Boger, M., Veynante, D.: In: Dopazo, C. (ed.) Advances in turbulence. isbn: 84-89925-65-8, pp. 449452. CIMNE, Barcelona (2000)

108. Duwig, C.: Flow Turbul. Combust. 79(4), 433 (2007)

109. Auzillon, P., Fiorina, B., Vicquelin, R., Darabiha, N., Gicquel, O., Veynante, D.: Proc. Combust. Inst. 33 33(1), 1331 (2011) 
110. Auzillon, P., Gicquel, O., Darabiha, N., Veynante, D., Fiorina, B.: Combust. Flame 159(8), 2704 (2012)

111. Butler, T., O’Rourke, P.: Proc. Comb. Inst. 16, 1503 (1977)

112. O’Rourke, P.J., Bracco, F.V.: J. Comp. Phys. 33, 185 (1979)

113. Thibaut, D., Candel, S.: Combust. Flame 113, 51 (1998)

114. Colin, O., Ducros, F., Veynante, D., Poinsot, T.: Phys. Fluids 12(7), 1843 (2000)

115. Charlette, F., Meneveau, C., Veynante, D.: Combust. Flame 131(1/2), 159 (2002)

116. Selle, L., Lartigue, G., Poinsot, T., Koch, R., Schildmacher, K., Krebs, W., Prade, B., Kaufmann, P., Veynante, D.: Combust. Flame 137, 489 (2004)

117. Sommerer, Y., Galley, D., Poinsot, T., Ducruix, S., Lacas, F., Veynante, D.: J. Turbulence 5 (2004)

118. Durand, L., Polifke, W.: In: Proceedings of the ASME Turbo Expo, vol. 2, pp. 869-878 (2007)

119. Broeckhoven, T., Freitag, M., Lacor, C., Sadiki, A., Janicka, J.: In: Kassinos, S.C., Langer, C.A., Iaccarino, G., Moin, P. (eds.) Complex Effects in Large Eddy Simulations. Lecture Notes in Computational Science and Engineering, vol. 56. Springer, Berlin Heidelberg (2007)

120. Schmitt, P., Poinsot, T., Schuermans, B., Geigle, K.: J. Fluid Mech. 570, 17 (2007)

121. Boileau, M., Staffelbach, G., Cuenot, B., Poinsot, T., Berat, C.: Combust. Flame 154(1-2), 2 (2008)

122. Roux, A., Gicquel, L., Sommerer, Y., Poinsot, T.: Combust. Flame 152(1-2), 154 (2008)

123. Staffelbach, G., Gicquel, L., Boudier, G., Poinsot, T.: Proc. Comb. Inst. 32, 2909 (2009)

124. Légier, J.P., Varoquié, B., Lacas, F., Poinsot, T., Veynante, D.: In: Pollard, A., Candel, S. (eds.) IUTAM symposium on turbulent mixing and combustion, vol. 70, pp. 315-326. Kluwer Academic Publishers, Dordrecht, The Netherlands (2002)

125. Gouldin, F.: Combust. Flame 68(3), 249 (1987)

126. Knikker, R., Veynante, D., Meneveau, C.: Proc. Comb. Inst. 29, 2105 (2002)

127. Wang, G., Boileau, M., Veynante, D.: Combust. Flame 158(11), 2199 (2011)

128. Wang, G., Boileau, M., Veynante, D., Truffin, K.: Combust. Flame 159(8), 2742 (2012)

129. Schmitt, T., Sadiki, A., Fiorina, B., Veynante, D.: Proc. Comb. Inst. 34(1), 1261 (2013)

130. Schmitt, T., Boileau, M., Veynante, D., Moureau, V.: In: Turbulent shear flow phenomena (TSFP8), Poitiers (2013)

131. Hawkes, E., Cant, S.: Proc. Comb. Inst. 28, 51 (2000)

132. Richard, S., Colin, O., Vermorel, O., Benkenida, A., Angelberger, C., Veynante, D.: Proc. Comb. Inst. 31(2), 3059 (2007)

133. Vermorel, O., Richard, S., Colin, O., Angelberger, C., Benkenida, A., Veynante, D.: Combust. Flame 156(8), 1525 (2009)

134. Weller, H., Tabor, G., Gosman, A., Fureby, C.: Proc. Comb. Inst. 27, 899 (1998)

135. Gao, F., O’Brien, E.: Phys. Fluids A 5(6), 1282 (1993)

136. Cook, A., Riley, J.: Phys. Fluids A 6(8), 2868 (1994)

137. Cook, A., Riley, J.: Combust. Flame 112, 593 (1998)

138. Olbricht, C., Stein, O., Janicka, J., van Oijen, J., Wysocki, S., Kempf, A.: Fuel 96(0), 100 (2012)

139. Haworth, D.: Prog. Ener. Comb. Sci. 36(2), 168 (2011)

140. Klimenko, A.: Fluid Dyn. 25(3), 327 (1990)

141. Bilger, R.: Phys. Fluids A 5(2), 436 (1993)

142. Klimenko, A., Bilger, R.: Prog. Energy Combust. Sci. 25(6), 595 (1999)

143. Mastorakos, E., Baritaud, T., Poinsot, T.: Combust. Flame 109, 198 (1997)

144. Navarro-Martinez, S., Kronenburg, A.: Proc. Comb. Inst. 31, 1721 (2007)

145. Navarro-Martinez, S., Kronenburg, A.: Proc. Comb. Inst. 32(1), 1509 (2009)

146. Triantafyllidis, A., Mastorakos, E., Eggels, R.: Combust. Flame 156(12), 2328 (2009)

147. Garmory, A., Mastorakos, E.: Proc. Comb. Inst. 33(1), 1673 (2011)

148. Giacomazzi, E., Battaglia, V., Bruno, C.: Combust. Flame 138, 320 (2004)

149. Berglund, M., Fedina, E., Fureby, C., Tegner, J., Sabel'nikov, V.: AIAA J. 48(3), 540 (2010)

150. Sabelnikov, V., Fureby, C.: Combust. Flame 160(1), 83 (2013)

151. Kerstein, A.: Comb. Sci. Tech. 60, 391 (1988)

152. Kerstein, A.: Combust. Flame 75(3-4), 397 (1989)

153. Kerstein, A.: J. Fluid Mech. 216, 411 (1990)

154. Kerstein, A.: J. Fluid Mech. 231, 361 (1991)

155. Kerstein, A.: Comb. Sci. Tech. 81, 75 (1992)

156. McMurthy, P., Gansauge, T., Kerstein, A., Krueger, S.: Phys. Fluids A 5(4), 1023 (1993)

157. McMurthy, P., Menon, S., Kerstein, A.: Proc. Comb. Inst. 24, 271 (1992)

158. Menon, S., McMurthy, P., Kerstein, A., Chen, J.: J. Propul. Power 10, 161 (1994)

159. Menon, S., Kerstein, A.: Proc. Comb. Inst. 24, 443 (1992) 
160. Menon, S., McMurthy, P., Kerstein, A.: In: Galperin, B., Orzag, S. (eds.) Large Eddy simulation of complex engineering and geophysical flows, pp. 87-314. Cambridge University Press, Cambridge (1993)

161. Undapalli, S., Srinivasan, S., Menon, S.: Proc. Combust. Inst. 32(1), 1537 (2009)

162. Park, J., Echekki, T.: Combust. Flame 159(2), 609 (2012)

163. Magnussen, B., Hjertager, B.: In: 16th Symposium (International) on combustion, pp. 719-727. The Combustion Institute, Pittsburgh (1976)

164. Veynante, D., Vervisch, L.: Prog. Energy Combust. Sci 28, 193 (2002)

165. Seffrin, F., Fuest, F., Geyer, D., Dreizler, A.: Combust. Flame 157(2), 384 (2010)

166. http://www.sandia.gov/tnf/abstract.html

167. Fiorina, B., Mercier, R., Kuenne, G., Ketelheun, A., Advic, A., Janicka, J., Geyer, D., Dreizler, A., Alenius, E., Duwig, C., Trisjono, P., Kleinheinz, K., Kang, S., Pitsch, H., Proch, F., Marincola, F., Kempf, A.: Submitted (2014)

168. Germano, M., Piomelli, U., Moin, P., Cabot, W.: Phys. Fluids A 3(7), 1760 (1991)

169. Pierce, C., Moin, P.: Phys. Fluids A 10(12), 3041 (1998)

170. Réveillon, J., Vervisch, L.: AIAA J. 36(3), 336 (1998)

171. Balarac, G., Pitsch, H., Raman, V.: Development of a dynamic model for the subfilter scalar variance using the concept of optimal estimators. Phys. Fluids 20(3) (2008)

172. Kaul, C.M., Raman, V., Knudsen, E., Richardson, E., Chen, J.: Proc. Combust. Inst. 34(1), 1289 (2013)

173. Jaberi, F., James, S.: Phys. Fluids A 10(7), 1175 (1998)

174. Knikker, R., Veynante, D., Meneveau, C.: Phys. Fluids 16(11), L91 (2004)

175. Hawkes, E., Chatakonda, O., Kolla, H., Kerstein, A.R., Chen, J.: Combust. Flame 159(8), 2690 (2012)

176. Pope, S.B.: New J. Phys. 6, 35 (2004)

177. Meier, W., Weigand, P., Duan, X., Giezendanner-Thoben, R.: Combust. Flame 150(1-2), 2 (2007)

178. Sweeney, M.S., Hochgreb, S., Dunn, M.J., Barlow, R.S.: Proc. Combust. Inst. 33(1), 1419 (2011)

179. Sweeney, M.S., Hochgreb, S., Barlow, R.S.: Combust. Flame 158(5), 935 (2011)

180. Moureau, V., Minot, P., Pitsch, H., Berat, C.: J. Comput. Phys. 221(2), 600 (2007)

181. Mercier, R., Moureau, V., Veynante, D., Fiorina, B.: (2014). Proceedings of the Combustion Institute (0)

182. Franzelli, B., Riber, E., Cuenot, B.: C. R. Mécanique 341(1-2), 247 (2013)

183. Jones, W.P., Lindstedt, R.P.: Combust. Flame 73, 233 (1988)

184. Peters, N.: Lecture Notes in Physics 241, 90 (1985)

185. Chen, J.Y., Dibble, R.W. In: Smooke, M.D. (ed.): Applications of reduced chemical mechanisms for the prediction of turbulent nonpremixed methane jet flames, vol. 384, pp. 193-226. Springer-Verlag, New York (1991)

186. Lu, T., Law, C.K.: Combust. Flame 154(4), 761 (2008)

187. Euler, M., Zhou, R., Hochgreb, S., Dreizler, A.: In: Proceedings of the European combustion meeting (2013)

188. Mercier, R., Schmitt, T., Veynante, D., Fiorina, B.: Proc. Combust. Inst. (2015)

189. Castela, M., Veríssimo, A.S., Rocha, A.M.A., Costa, M.: Combust. Sci. Technol. 184(2), 243 (2012) 